\title{
Macroeconomic Potentials of Transatlantic Free Trade: A High Resolution Perspective for Europe and the World
}

\author{
Gabriel Felbermayr \\ Benedikt Heid \\ Mario Larch \\ Erdal Yalcin
}

CESIFO WORKING PAPER NO. 5019

CATEgory 8: TRAdE POLICY

OCTOBER 2014

An electronic version of the paper may be downloaded

- from the SSRN website:

- from the RePEc website:

- from the CESifo website:

www.SSRN.com

Www.RePEc.org

www.CESifo-group.org/wp

\section{CESifo}




\title{
Macroeconomic Potentials of Transatlantic Free Trade: A High Resolution Perspective for Europe and the World
}

\begin{abstract}
The proposed Transatlantic Trade and Investment Partnership (TTIP) is the most significant trade policy initiative since the Uruguay Round (1986 to 1994). It would create a free trade zone covering $45 \%$ of world GDP. However, critics dismiss the possible welfare gains as small compared to the risks. In this paper, we provide results based on a structurally estimated general equilibrium trade model. Assuming that the TTIP will reduce transatlantic trade costs by as much as existing bilateral agreements have reduced trade costs between their trade partners, we find that a TTIP could result in very substantial gains for Germany $(+3.5 \%)$, Europe (3.9\%), and the world (+1.6\%), but that it could also harm third countries.
\end{abstract}

Keywords: trade agreements, structurally estimated general equilibrium model, Transatlantic Trade and Investment Partnership.

Gabriel Felbermayr

Ifo Institute - Leibniz Institute for

Economic Research

at the University of Munich

Poschingerstrasse 5

Germany-81679 Munich

felbermayr@ifo.de

Mario Larch

Department of Economics

University of Bayreuth

Germany - 95440 Bayreuth

mario.larch@uni-bayreuth.de

\author{
Benedikt Heid \\ Department of Economics \\ University of Bayreuth \\ Germany-95440 Bayreuth \\ benedikt.heid@uni-bayreuth.de
}

\author{
Erdal Yalcin \\ Ifo Institute - Leibniz Institute for \\ Economic Research \\ at the University of Munich \\ Poschingerstrasse 5 \\ Germany - 81679 Munich \\ yalcin@ifo.de
}




\title{
Macroeconomic potentials of transatlantic free trade: A high resolution perspective for Europe and the world
}

\author{
Gabriel Felbermayr, Benedikt Heid, Mario Larch, and Erdal \\ Yalcin \\ Ludwig Maximilians University Munich, ifo Institute Munich, and CESifo; University of \\ Bayreuth; University of Bayreuth and CESifo; ifo Institute Munich and CESifo.
}

\section{INTRODUCTION}

Since July 2013 the US and the EU have been negotiating a comprehensive agreement on facilitating trade and investment across the Atlantic. The proposed Transatlantic Trade and Investment Partnership (TTIP) would be the largest free trade area in the world. In 2012, the two regions accounted for more than $45 \%$ of global value added in current dollars and for $30 \%$ of trade (exports and imports of goods and services) in the world. In February 2013, a high-level working group recommended negotiations aiming at a "comprehensive" and "ambitious" agreement. The sheer size and the depth of the proposed undertaking suggest that it could have strong effects for EU member states, the US, third countries, and the world trading system.

In many EU member states, the proposed TTIP is discussed very controversially despite the fact that the scope and details of the agreement are still unknown to everyone. Proponents of an agreement between the EU and the US point towards economic gains and hope that a TTIP can pave the way towards an overhaul of the multilateral world

Preliminary version of a paper prepared for the $60^{\text {th }}$ Panel Meeting of Economic Policy, October 2014 (revised Sept 19, 2014). We thank the editor, Thorsten Beck, and two anonymous referees for their invaluable advice. We are also grateful to Sebastian Benz, Kerem Cosar, Anne-Célia Disdier, Heribert Dieter, Lionel Fontagné, Joseph Francois, Len-Kuo Hu, Sébastien Jean, Sybille Lehwald, Jacques Pelkmans, Laura Márquez Ramos, Uli Schoof, and seminar participants at Brussels, Berlin, Fudan, Göttingen, Heidelberg, Munich, Ningbo, Taipeh, and Vienna for helpful comments. All remaining errors are ours. 
trade order. Critics dismiss the gains as small and fear that a trade deal may trigger a race to the bottom in health, safety, labor, and environmental standards. They also argue that a TTIP may undermine the World Trade Organization (WTO) as the relative importance of WTO-covered trade for both the EU and the US goes down.

In this paper, we focus on the potential welfare gains from a TTIP for European member states, the US, and third countries. Our contribution is to employ a structurally estimated general equilibrium model. Such models have been recently used to quantify the gains from trade, but researchers are only starting to apply them to trade policy analysis. ${ }^{1}$ Central to our strategy, we provide econometric estimates of the average trade cost effect of existing agreements and assume that the trade cost reducing potential of a TTIP is equal to this average.

The traditional approach to carry out ex ante analysis of trade policy analysis is to use large scale computable general equilibrium (CGE) models. In the context of TTIP, such an approach has been chosen by Francois, Manchin, Norberg, Pindyuk and Tomberger (2013, henceforth FMNPT) or by Fontagné, Gourdon and Jean (2013). We do not view our work as a substitute to CGE modeling, but rather as complementary and as an important robustness analysis. ${ }^{2}$

One advantage of our approach is that the parameters of the model are estimated on exactly the data that the model is supposed to replicate in its baseline equilibrium. One of the key unknowns for which estimates are required is the initial matrix of trade costs. Trade costs include not only political barriers such as tariffs, or identifiable non-tariff measures, but also the costs of overcoming geographical, linguistic, or cultural distance. The recent empirical trade literature has emphasized how big trade costs still are despite all the talk about a flat world - and how relevant non-policy related trade costs are relative to costs directly caused by policy. Trade agreements directly affect the latter type of cost; however, they may also very well change private and public incentives to invest into measures that bring other types of trade costs down - e.g., by improved harbor facilities. It is commonly understood that import tariffs of both the EU and the US are relatively low. As shown in Felbermayr and Larch (2013), the weighted average tariff on manufactured goods is about $2.8 \%$ for both regions; the weighted tariffs on agricultural goods are only slightly higher (but more asymmetric). In contrast, overall trade costs are estimated to be much higher. For trade amongst industrialized countries, Anderson and van Wincoop (2004) report an ad valorem equivalent of international trade costs (transportation costs and border-related costs) of $74 \% .^{3}$ Only $8 \%$ thereof are attributable to tariffs and non-tariff measures (NTMs). Over the last 15 years or so, improved data and methods have corroborated the large role of trade costs; see the recent survey by Head and Mayer (2014) on this topic.

\footnotetext{
${ }^{1}$ The literature is nicely summarized in the chapter of Costinot and Rodriguez-Clare (2014) in the forthcoming fourth edition of the Handbook of International Economics.

${ }^{2}$ In Felbermayr, Larch, Flach, Yalcin and Benz (2013), we have worked with a setup similar to the one employed in this paper. However, the present study uses a much larger country sample (173) and more recent data (2012).

${ }^{3}$ See page 693 in Anderson and van Wincoop (2004). Note that within-country trade costs add an additional ad valorem cost equivalent of $55 \%$, so that total trade costs amount to $170 \%(1.74 * 1.55)$.
} 
When estimating the baseline trade cost matrix, it is necessary to account for the effect of existing preferential trade agreements (PTAs) on trade costs. In a meta study, Cipollina and Salvatici (2010) have found that - over 1,827 estimates from 85 studies the average PTA coefficient implies an increase in bilateral trade by more than $80 \%$. Many of the included estimates come from regression designs that do not yet integrate what Head and Mayer (2014) have called the "fixed effects revolution" in gravity modeling, and very few of them account for the problem that PTAs are likely to be endogenous to trade shocks. As argued by Baier and Bergstrand (2007) and Egger, Larch, Staub and Winkelmann (2011, henceforth ELSW), dealing with the non-random selection of country pairs into PTAs yields even larger point estimates, even in very recent trade data. The likely reason for this result is that the existence of high unobserved non-tariff trade barriers lowers trade between two countries, but also increases the likelihood of PTAs, since the potential trade cost reductions are higher. These numbers imply that, for reasonable values of the unknown trade elasticity, the average PTA does much more than just eliminate the remaining (low) tariff barriers. They also imply that existing PTAs have been successful in bringing NTMs down.

Knowing the effect of PTAs on trade costs has the added advantage that it provides a natural scenario for a proposed future trade agreement: the trade cost reductions found in existing agreements serve as a sensible expectation of what a TTIP could bring about for transatlantic trade. Additionally, it ensures that the expected trade effect of TTIP would be exactly in line with what we know from existing agreements.

This strategy has two important advantages. First, it does not require external information on non-tariff measures. Estimates on such measures exist, but they are patchy. Berden, Francois, Thelle, Wymenga and Tamminen (2009) summarize the evidence for the transatlantic trade relationship, but we would need accurate data for every single bilateral trade link covered in the model. This would be excessively expensive: we include 173 nations, that is, we base our predictions on a matrix of almost 30,000 yearly aggregate trade flows $(173 * 172=29,756)$ and would, therefore, need data on NTMs for all these links. Second, we do not need to specify by how much NTMs would fall in the proposed agreement, but we can use the estimated PTA effect from the gravity model. The caveat, clearly, is that TTIP both covers a larger share of world GDP and is intended to be deeper than the average existing agreements, to that our method may actually underestimate the true effect. We therefore also provide additional results covering a wide range of plausible values of estimated PTA effects.

We work with the simple Krugman (1980) general equilibrium trade model with monopolistic competition and fixed dyadic entry costs proposed by Egger and Larch (2011). This model allows for an extensive margin, i.e., it rationalizes the fact that not all country-pairs feature strictly positive trade flows. The model gives rise to a gravity equation which can be implemented by means of an econometric two-part model, and which yields estimates for the trade cost matrix and for the partial effect of concluding a PTA. In the base year of 2012, the model explains $93 \%$ of the variation in the observed trade flow data $\left(\mathrm{R}^{2}\right.$ of $\left.93 \%\right)$. 
In the second step, we simulate the effects of switching the PTA effect on in the 56 trade pairs involved in the TTIP. We calculate the associated counterfactual GDPs, price indices and levels of real per capita income (equivalent variation). In our benchmark exercise, we find that TTIP increases real income by $3.9 \%$ in the EU 28 , by $4.9 \%$ in the US, but lowers it by $0.9 \%$ in the rest of the world. These numbers are substantially higher than those predicted by FMNPT who predict an increase of $0.48 \%$ for the EU. While that study puts the long-run average gain from a TTIP in Europe at about 136 Euro per capita (545 Euro for a four person household), our estimates put it about 1,118 Euro. $^{4}$

Our numbers hide a substantial degree of heterogeneity both within the EU and between the EU and the US. We predict larger potential welfare gains in EU member states with peripheral geographical positions compared to more central states. For example, Germany could gain 3.5\% in the long run, while the gains in Spain are around $5.6 \%$. The reason for this is that more central countries naturally have lower average trade costs with other EU member states, which has made EU integration particularly beneficial for them, but also implies relatively high trade costs with the US. We also find that the US systematically gains more from a TTIP than the EU. This is a natural consequence from the fact that a TTIP offers better access to imports from 28 different member states for the US. This provides the American consumer with higher gains from more product varieties than the European one. When we aggregate all EU countries into a single economy, the difference between the EU and the US shrinks.

On the global level, countries having preferential trade agreements with the EU or the US would lose due to preference erosion. These losses increase strongly in the relative importance of the EU or the US in those countries' exports. So, at the higher end, we find losses of about 3.1\% in Canada, 2.6\% in Mexico and 1.6\% in Turkey. At the lower end, countries which are less exposed to the EU or US markets, lose less, e.g., China $0.5 \%$. This effect results from trade diversion. On average, countries not covered by a TTIP lose $0.9 \%$ while the world in total gains $1.6 \%$.

The existence of negative third country effects is well known from the theory of preferential trade agreements and goes back to at least Jacob Viner's (1950) book The Customs Union Issue. Some analysts hope that the focus on NTMs and regulatory cooperation in $21^{\text {st }}$ century PTAs make the classical concerns redundant; for a prominent example see Baldwin (2011). Indeed, if a TTIP sets joint standards and norms, or if regulatory convergence leads to lower market entry barriers relative to all trade partners, outsiders could benefit as well. Hence, FMNPT assume that trade cost savings across the Atlantic will spill over to third countries.

However, in line with conclusions presented in the 2012 World Trade Report, our reading of the available empirical evidence suggests that such spill-overs are by no means guaranteed. First, the agreement could very well lead to mutual recognition of national standards within TTIP rather than to a world standard. In this case, whether

\footnotetext{
${ }^{4}$ These calculations are based on a GDP per capita of 28,385 Euro. Note, however, that comparisons across studies are problematic. The FMNPT exercise embeds its counterfactual analysis into a hypothetical future world (2027); while we refer to the year 2012 .
} 
third countries are discriminated or not, depends on rules of origins. Second, TTIP does include many classical market access elements (public procurement, quantitative restrictions in agri-food sector, services, etc.). At the very least, our results on third countries suggest that negotiators need to make sure that discriminatory effects of the agreement are indeed minimized.

We subject our main results to a large number of sensitivity checks and robustness analysis. Most importantly, we find that the estimated effect of the average PTA on trade costs is the single most important parameter that drives the magnitude of welfare effects. Indeed, when setting that parameter to the value that ensures that the welfare gains predicted by our model for the US are identical to those computed by FMNPT, we get a hypothetical PTA coefficient that is at least 5 times lower than the ones obtained in the modern econometric literature. ${ }^{5}$

Before proceeding, let us acknowledge certain limitations of our approach: First, because of its single sector nature, it cannot do justice to the very specific structure of sector specialization in different countries and therefore misses potentially interesting heterogeneous industry-level effects. However, its relative simplicity makes the interpretation of the results relatively easy and allows relating our exercise to the quantitative trade models surveyed in Costinot and Rodriguez-Clare (2014). Moreover, the parsimony implies a strong degree of discipline: the results are driven by few transparent assumptions. Finally, the single-sector approach allows for additional flexibility and adjustment from the economy to a trade cost shock, at least in a reducedform sense. Models with multiple sectors are usually restricted by invariant input-output relationships and constant expenditure shares, partly restricting the shock-induced adjustment across sectors. This may explain, amongst other things, why we find higher effects than FMNPT.

Second, our top-down approach on trade costs and the single sector perspective clearly lower the utility of our exercise for the daily troubles of negotiators. However, our method does provide a credible quantitative guideline to policy makers as to whether it is worth investing political capital and to the wider public as to whether such an agreement would be worth any non-economic risks or costs.

The remainder of this paper is structured as follows. In Section 2 we discuss some important facts that motivate our research strategy. In Section 3 we explain our model and our econometric approach. Section 4 briefly discusses the data and the structure of trade costs. Section 5 presents the results of our benchmark model and investigates their sensitivity to key assumptions. Section 6 investigates the role of potential positive spillover effects from a TTIP and its interaction with other, currently debated potential regional trade agreements. Section 7 contains various robustness checks. Finally, Section 8 concludes with a discussion of trade policy implications.

\footnotetext{
${ }^{5}$ Notice, however, that the FMNPT framework differs in many dimensions from ours; so, this finding has no implications on the empirical fit of the results presented in FMNPT.
} 


\section{SOME IMPORTANT FACTS AND OUR RESEARCH STRATEGY}

In this section we present some facts that are relevant for our particular research design. For further details, we refer the reader to FMNPT, Felbermayr and Larch (2013), or Hamilton and Quinlan (2014) who provide broad coverage of pertinent trends and facts.

\subsection{Transatlantic trade potential and trade barriers}

Most favored nations (MFN) import duties imposed by either the EU or the US have been lowered in various rounds of multilateral trade liberalization. As discussed in Felbermayr and Larch (2013), the overall weighted average tariff on industrial goods is $2.8 \%$ for both the EU and the US; in the area of agriculture the average is slightly higher (3.8\% in the EU, $2.8 \%$ in the US). These averages mask a high degree of variation across industries. Peak tariff rates may reach $350 \%$ in the U.S. and $75 \%$ in the EU in sectors such as alcoholic beverages and tobacco, or in the agri-food area. The EU median is $3.5 \%$, while the U.S. features a median of $2.5 \%$; the (unweighted) arithmetic mean is more than a percentage point higher than the median. This latter fact testifies to a substantial amount of skewness in the distribution of tariffs across products. In both, the US and the EU, at least $25 \%$ of all product lines are not subject to import duties. However, it is also true that $25 \%$ of product lines are subject to tariff rates higher than $6.5 \%$ (EU) and $5.5 \%$ (US), respectively.

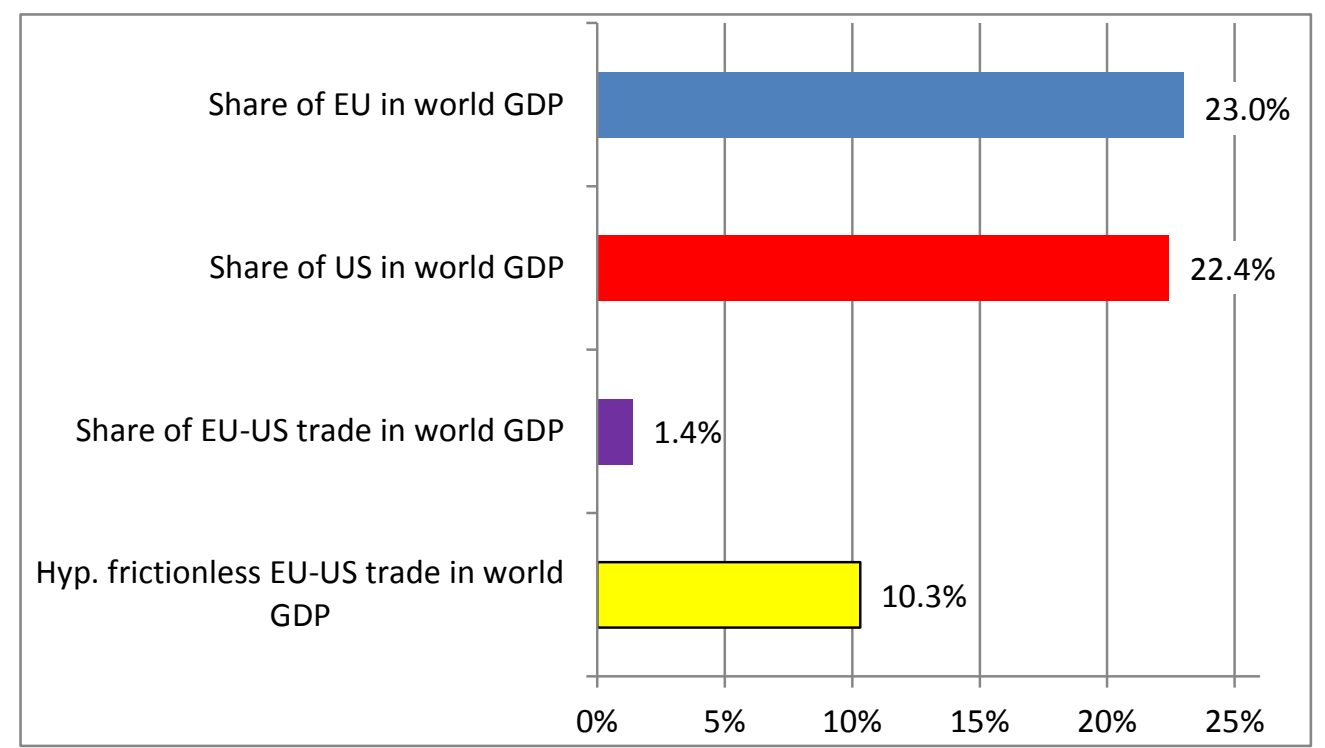

Figure 1. Trade potential and observed trade across the Atlantic

Source: Authors' calculations based on data from the World Bank's WDI statistics and the WTO's ITS statistics.

However, despite relatively low tariffs, there seems to be untapped potential in the EUUS trade relation. This can be seen by comparing observed trade volumes to those 
predicted by simple trade models under the assumptions of (i) frictionless trade, (ii) identical preferences, and (iii) product differentiation. In these hypothetical textbook circumstances (see, e.g., Feenstra (2004), Chapter 5), US imports (of goods and services) from the EU should equal the EU's share in world output (the EU's share in world GDP, i.e., $23.0 \%$ as of 2012), times total US expenditure (the US GDP, adjusted for current account imbalance, amounting to 16,606 bn dollars). This would yield imports of 3,818 bn dollars. Similarly, EU imports from the US should amount to 3,698 bn dollars (EU expenditure of 16,504 bn dollars times US share in world GDP, 22.4\%). The sum, i.e., total predicted trade across the Atlantic, would be worth $10.3 \%$ of world GDP (which amounts to 74,490 bn dollars in 2012); see Figure 1.

Observed total trade (EU exports of 550 bn dollars, US exports of 455 bn dollars), in contrast, amounts only to $1.4 \%$ of world GDP (71,697 bn dollars). So, in the year of 2012 , only about $13.4 \%$ of the hypothetical benchmark trade potential is utilized. This is a recurrent observation in many bilateral trade relationships. Note that the $1.4 \%$ is an overestimation, since it refers to gross trade and not to value-added trade. Using data from the WTO-OECD Trade in Value Added (TiVA) database for the year 2009, similar calculations put observed transatlantic trade at $1.2 \%$ of world GDP.

These considerations suggest that assumptions (i) to (iii) used to predict the benchmark cannot possibly hold. However, they differ with respect to the likelihood of failure. Assumption (iii) - product differentiation - is broadly realistic, in particular in the context of EU-US trade. There are few bilateral trade links in which the Grubel-Lloyd index of intra-industry trade would be higher; see Felbermayr and Larch (2013). More generally, the very good empirical fit of empirical trade flow equations (the so called gravity equation, see below) is consistent with this assumption. Assumption (ii) identical preferences - is more problematic. However, while home bias may be pervasive, there is little hard evidence for it and economists are generally reluctant to fit models to the data by allowing for (arbitrary) differences between agents/countries. Finally, assumption (i) - the absence of trade costs - is clearly violated: tariffs in transatlantic trade are not zero, there is strong direct evidence that non-tariff measures exist and are important, and other barriers (not directly related to policy) are also pervasive. This is in line with empirical evidence (e.g., see the survey by Anderson and van Wincoop, 2004; or Chen and Novy, 2012). In the following, we maintain assumptions (ii) and (iii) and attribute the entire gap between actual and hypothesized trade to trade costs.

Assuming a trade elasticity $\varepsilon$, it is easy to back out the ad valorem equivalent (AVE) of trade costs that can generate the pattern shown in Figure 1. Indeed, the AVE of trade costs can be computed by applying $\left(T_{i j} / \widehat{T}_{i j}\right)^{-1 / \varepsilon}$, where $T_{i j}$ and $\widehat{T}_{i j}$ are the observed and the predicted (from the frictionless model) trade volumes, respectively. The trade elasticity measures how a percentage change in trade costs maps into a percentage change in trade flows. Figure 2 shows those AVEs for different values of the trade elasticity. It also differentiates between observed bilateral gross trade (from 2012) and bilateral trade in value added (for 2009). It suggests that the AVEs of trade costs are substantial. For a trade elasticity of 7 (the value used in our subsequent analysis), the 
AVE ranges between 33 and $45 \%$. With a trade elasticity of 4, as in Bernard, Redding and Schott (2007), the AVE lies between 65 and 92\%.

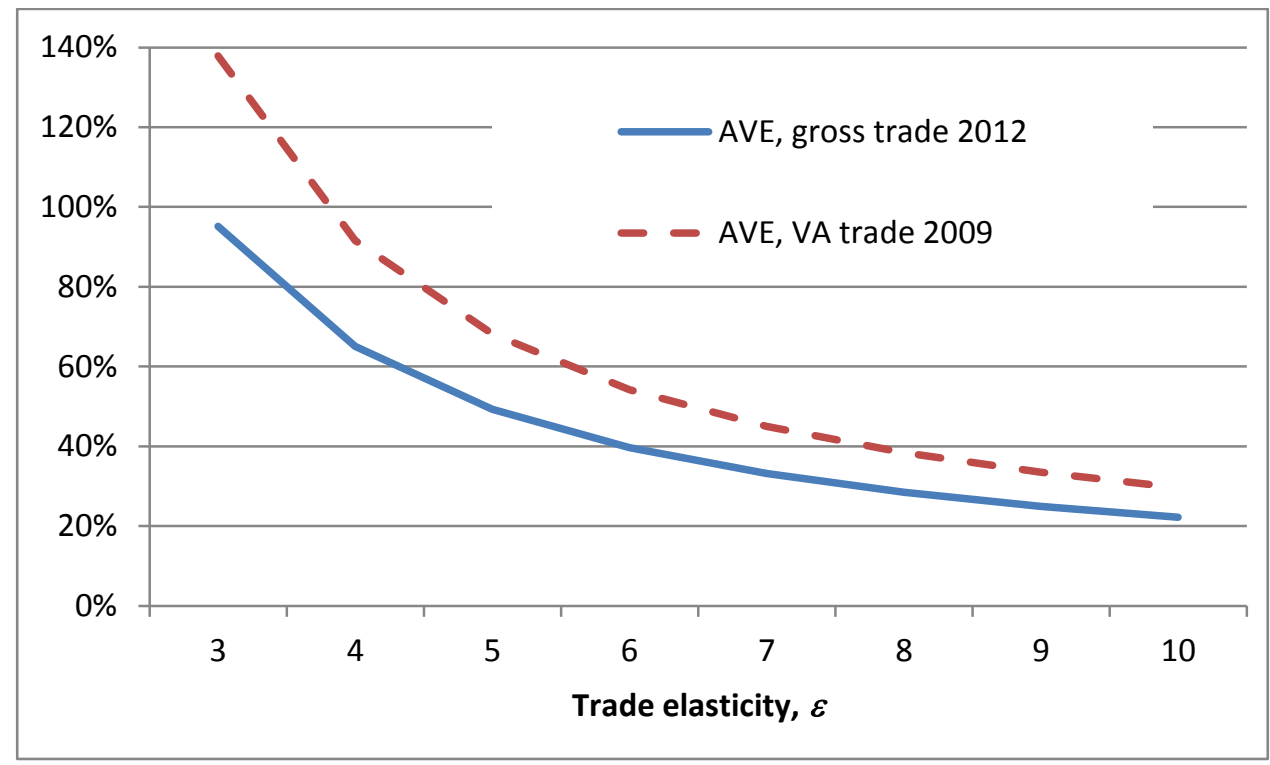

Figure 2. Ad valorem equivalents (AVE) of trade costs across the Atlantic

Source: Authors' calculations based on data from the WTO ITS statistics and from the TiVA database.

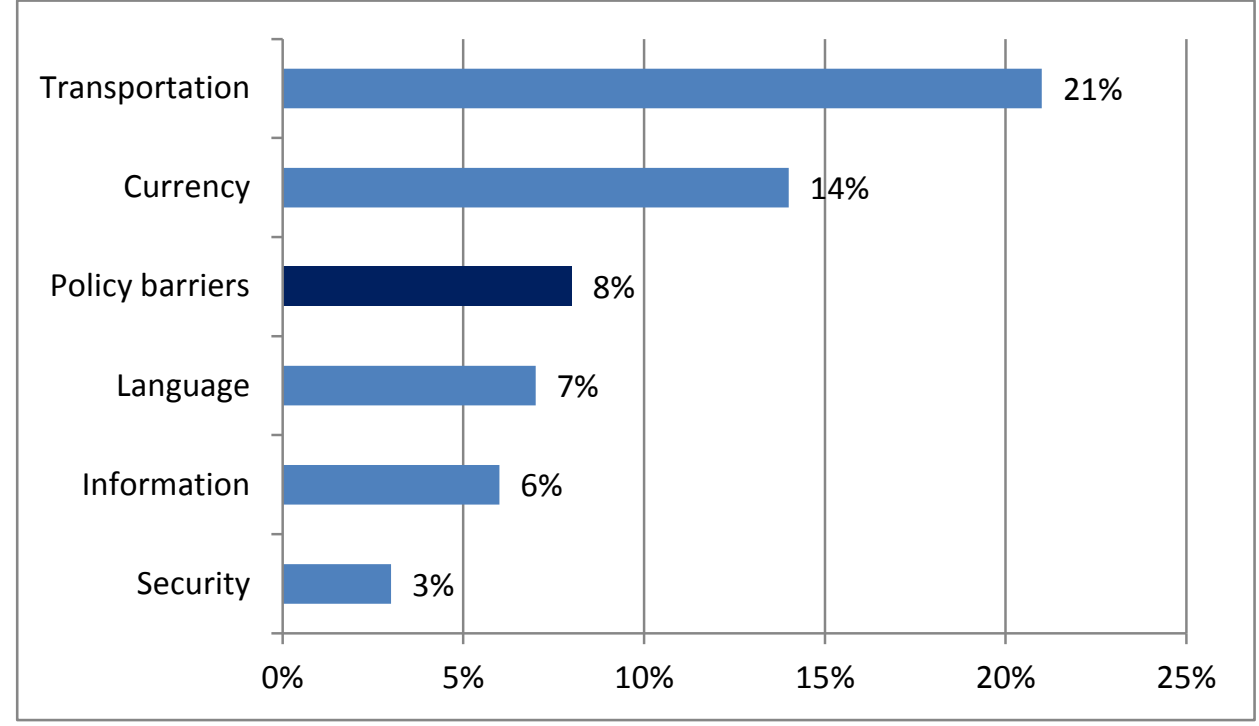

Figure 3. Ad valorem equivalents of trade costs amongst industrialized countries

Source: Anderson and van Wincoop (2004, p. 693). 
The recent literature has put much effort into a better understanding of trade costs. Figure 3 presents a breakdown due to Anderson and van Wincoop (2004). These authors distinguish between costs related to (i) the transportation of goods (including things such as insurance, time costs etc.), (ii) the conversion and management of foreign exchange, (iii) policy barriers such as tariffs and non-tariff measures, (iv) translation requirements, (v) informational asymmetries and (vi) security. The total ad valorem equivalent builds up to $74 \%(1.21 * 1.14 * 1.08 * 1.07 * 1.06 * 1.03=1.74)$. This number resonates well with the data plotted in Figure 2. For trade elasticities ranging between 4 and 7, and depending on the exact nature of trade data, transatlantic trade costs are between $32 \%$ and $92 \%$.

\subsection{Preferential trade agreements and trade costs}

Cipollina and Salvatici (2010) provide a meta study about the large literature on the trade flow effects of PTAs. Across 1,827 point estimates (mostly reduced-form estimates with $\log$ trade as the dependent variable, and controlling for a host of other relevant determinants of trade flows), they find an average effect of 0.59. Accordingly, the presence of a PTA would boost bilateral trade by about $80 \%(\exp (0.59)=1.80)$.

Table 1. Causal trade cost effects of existing PTAs, percentage points

\begin{tabular}{|c|c|c|c|c|}
\hline \multirow[b]{2}{*}{ Source } & & \multirow[b]{2}{*}{$\begin{array}{c}\text { point } \\
\text { estimate }\end{array}$} & \multicolumn{2}{|c|}{ trade elasticity } \\
\hline & & & 4 & 7 \\
\hline Head \& Mayer (Handbook, 2014) & Tab. 4, all gravity & 0.59 & $-13.70 \%$ & $-8.10 \%$ \\
\hline Head \& Mayer (Handbook, 2014) & Tab. 4, struct. gravity & 0.36 & $-8.60 \%$ & $-5.00 \%$ \\
\hline Baier \& Bergstrand (JIE, 2007) & Tab. 4, col. (4) & 0.68 & $-15.6 \%$ & $-9.3 \%$ \\
\hline Egger et al. (AEJ, 2011) & Tab. 3, col. (7) & 1.21 & $-26.1 \%$ & $-15.9 \%$ \\
\hline Baier \& Bergstrand (JIE, 2009) & Tab 5, col. (13) & 1.08 & $-23.7 \%$ & $-14.3 \%$ \\
\hline Baier \& Bergstrand (JIE, 2009) & Tab 5, col. (12) & 0.77 & $-17.5 \%$ & $-10.4 \%$ \\
\hline Magee (BEP, 2003) & Tab 5, col. (2) & 2.20 & $-42.3 \%$ & $-27.0 \%$ \\
\hline Egger \& Larch (EER, 2011) & Tab 2, col. (9) & 0.55 & $-12.9 \%$ & $-7.6 \%$ \\
\hline
\end{tabular}

Note: All estimates from published papers, significant at the $1 \%$ level; comprehensive recent samples; number of countries $>100$ countries. Published estimates of trade effects have been translated into trade cost effects following Anderson van Wincoop (2003). Specifically, we calculate the percentage tariff equivalent of trade cost reductions of a PTA as $\left(\exp (\delta)^{-1 /(1-\sigma)}-1\right) \times 100 \%$, where $\delta$ is the point estimate and $\sigma=\varepsilon-1$.

More recent studies have estimated gravity models that are consistent with trade models (such as the one that we use in this paper) so that the estimated parameters can be interpreted as parameters of the underlying structural economic model. Moreover, they have taken care of the obvious possibility of non-random selection of country pairs into PTAs. Agreements may be concluded where either trade is expected to be high anyway or where it pays most to remove NTMs. Table 1 presents some of the most 
prominently published estimates, which deal convincingly with both problems. All mentioned estimates are based on large country samples including developed and developing countries, and admit a causal interpretation.

In most of these papers, PTAs appear to reduce trade costs by more than the $8 \%$ benchmark attributed to trade policy by Anderson and van Wincoop (2004). It follows that PTAs have effects that go beyond the simple elimination of tariffs or available measures of non-tariff measures, on which we still have only very partial information; see the discussion in Anderson and van Wincoop (2004). As our knowledge improves (see Berden, Francois, Thelle, Wymenga and Tamminen, 2009), the gap between bottom-up and top-down (or direct and indirect; see Chen and Novy, 2012) estimates should converge. Moreover, it is conceivable that the expectation of increased trade through lower tariffs and NTM-related costs may incentivize private and public agents to invest in further reductions of bilateral trade barriers, for instance, in infrastructure (such as liquid natural gas terminals), in specific human capital (e.g., US law students specializing in EU law), or to step up cooperation in monetary policy with the effect of lowering exchange rate volatility. These actions would not be legally mandated by the trade agreement itself, but they would still be causally related to the agreement and lead to lower bilateral trade costs in the medium to long run.

We will explain below why our preferred estimate is the one by ELSW and why we work with a trade elasticity of 7 . Here it suffices to note that these choices imply that across more than 121 trade agreements covered in this paper - the trade cost reduction resulting from PTAs is about 17 percent. This is the scenario that we also assume for a TTIP in our baseline scenario. It includes all the direct and indirect ways through which PTAs may lower trade costs. However, we also undertake robustness checks concerning a wide range of plausible values for the trade cost reducing effect of PTAs.

\section{THEORETICAL FRAMEWORK AND EMPIRICAL MODEL}

This chapter presents the general equilibrium model and the empirical methodology used in this study. Readers not interested in the structural estimation of general equilibrium trade models are invited to skip this section and continue at Chapter $4{ }^{6}$

\subsection{A simple general equilibrium model of world trade}

We assume that consumers derive utility from consuming a large number of goods which are imperfect substitutes to each other. The constant elasticity of substitution between goods is given by $\sigma>1$. In line with the literature, preferences feature love for variety: having access to a larger number of goods makes them better off.

We assume that firms within each country are homogeneous and that they are monopolistically competitive, i.e., they have market power in the specific variety that they sell, but they cannot influence macroeconomic aggregates. There are two types of

${ }^{6}$ Also see Egger and Larch (2011) for a comprehensive discussion of the model. 
trade costs: variable trade costs (including, when applicable, tariffs), and bilateral fixed market entry costs.

By selling to market $j$, a firm from country $i$ makes profits $\pi_{i j}=\left(p_{i}-c_{i}\right) x_{i j}-f_{i j}$, where $p_{i}$ is the ex-factory price charged by the firm, $c_{i}$ denotes variable production costs, and $f_{i j}$ is the fixed cost of selling to market $j$. With total expenditure (GDP) of country $j$ being given by $y_{j}$, and under the appropriate budget constraint, demand for a variety from country $i$ in country $j$ is given by $x_{i j}=p_{i}^{-\sigma} t_{i j}^{1-\sigma} P_{j}^{\sigma-1} y_{j}$, where $t_{i j} \geq 1$ are variable trade costs and $P_{j}$ is the aggregate price index. It is negatively related to the degree of competition in country $j$ : the lower it is, the harder it is for the exporter to sell. Monopolistic pricing implies $p_{i}-c_{i}=p_{i} / \sigma$ and firms from $i$ export to $j$ only if $p_{i} x_{i j} \geq \sigma f_{i j}$. Let us define the indicator function $\mathbb{I}_{i j}$ to take value one if that inequality is met and zero else. Also let the number of producers in country $i$ be given by $n_{i} \cdot{ }^{7}$

Then, aggregate nominal goods exports from $i$ to $j$ are

$$
n_{i} p_{i} x_{i j}=X_{i j}=\mathbb{I}_{i j} n_{i} p_{i}^{1-\sigma} t_{i j}^{1-\sigma} P_{j}^{\sigma-1} y_{j}
$$

A country's sales to any of the $C$ countries (including to the home market) add up to GDP, and thus

$$
y_{i}=n_{i} p_{i}^{1-\sigma} \sum_{j=1}^{C}\left(\mathbb{I}_{i j} t_{i j}^{1-\sigma} P_{j}^{\sigma-1} y_{j}\right) .
$$

Now, defining world GDP as $y_{W}=\sum_{j=1}^{C} y_{j}$ one can replace $n_{i} p_{i}^{1-\sigma}$ by $y_{i} / y_{W} \Pi_{i}^{1-\sigma}$. This yields

$$
X_{i j}=\mathbb{I}_{i j} \frac{y_{i} y_{j}}{y_{W}} t_{i j}^{1-\sigma} \Pi_{\mathrm{i}}^{\sigma-1} \mathrm{P}_{\mathrm{j}}^{\sigma-1}
$$

where, $\forall i, j$,

$$
\Pi_{i}^{1-\sigma}=\sum_{j=1}^{c}\left(\mathbb{I}_{i j} t_{i j}^{1-\sigma} \mathrm{P}_{\mathrm{j}}^{\sigma-1} \mathrm{y}_{\mathrm{j}} / \mathrm{y}_{\mathrm{w}}\right), \quad \mathrm{P}_{j}^{1-\sigma}=\sum_{i=1}^{c}\left(\mathbb{I}_{i j} t_{i j}^{1-\sigma} \Pi_{\mathrm{j}}^{\sigma-1} \mathrm{y}_{\mathrm{i}} / \mathrm{y}_{\mathrm{W}}\right) ;
$$

see Egger and Larch (2011) for details on the derivations. As one can see, $\Pi_{i}^{1-\sigma}$ and $\mathrm{P}_{j}^{1-\sigma}$ are functions of GDPs and trade costs. The above gravity equation can be understood as a demand equation: the elasticity $\sigma>1$ describes how a change in the aggregate price for foreign goods (triggered, i.a., by variation in trade costs $t_{i j}$ ) affects demand for foreign varieties in the domestic economy. This elasticity is closely related to the trade elasticity, which is just $\varepsilon=\sigma-1$. The terms $\Pi_{i}$ and $P_{j}$ are what Anderson and van Wincoop $(2003,2004)$ called outward and inward multilateral resistance terms (MRT), respectively. They capture how trade costs with other countries affect demand of country $j$ for goods from $i$. More precisely, $\Pi_{i}$ summarizes the trade costs for exporters as if they would face an integrated world market where they can sell their products. Similarly, $P_{j}$ summarizes the trade costs for consumers as if they would buy their products from an integrated world market. ${ }^{8}$ The MRT terms quantify the trade diversion effects that the theoretical literature has discussed at least since Viner (1950).

For our $C$ country world, we may now state equilibrium as follows. There are $C$ equations that determine GDP as the sum over sales to all countries:

\footnotetext{
${ }^{7}$ Note that the number of producers/varieties is a function of a country's size, as shown in equation (8) in Bergstrand, Egger, and Larch (2013).

${ }^{8}$ See Anderson and Yotov (2010) and the references therein on the integrated world market interpretation.
} 


$$
y_{i}=\sum_{j=1}^{C}\left(\mathbb{I}_{i j} \frac{y_{i} y_{j}}{y_{W}} t_{i j}^{1-\sigma} \Pi_{\mathrm{i}}^{\sigma-1} \mathrm{P}_{\mathrm{j}}^{\sigma-1}\right),
$$

and there are $2 \times C$ equations given by (3) determining the multilateral resistance terms $\Pi_{i}$ and $P_{j}$. Given estimates of $t_{i j}, \sigma$, and $\mathbb{I}_{i j}$, it is thus possible to solve for the $C$ unknown levels of GDP. Real GDP follows by computing $y_{i} / P_{i}$.

\subsection{Structural estimation}

To calculate the changes in trade flows and real GDPs, we need consistent estimates of trade costs. We follow the gravity literature and proxy $t_{i j}$ by the bilateral distance between countries $\left(D I S T_{i j}\right)$, an indicator whether the countries share a common border $\left(B O R D_{i j}\right)$, an indicator whether the countries share a common colonial past $\left(C O L O N Y_{i j}\right)$, and an indicator whether the countries share a common language $\left(L A N G_{i j}\right)$. As we are interested in the effects of a TTIP, we will use information on preferential trade agreements (PTAs) concluded in the past in order to learn the average effect of trade agreements on trade costs. This way, we capture a realistic and feasible reduction of costs associated to lower NTMs without the need to have direct measures of NTMs.

Hence, trade costs $t_{i j}$ are proxied as follows:

$$
t_{i j}^{1-\sigma}=\exp \left(\beta_{1} \log D I S T_{i j}+\beta_{2} B O R D_{i j}+\beta_{3} L A N G_{i j}+\ldots+\delta P T A_{i j}\right) .
$$

Substituting equation (5) into equation (2), we end up with the following multiplicative model (see Egger and Larch, 2011):

$$
X_{i j}=\mathbb{I}_{i j} \exp \left(\boldsymbol{Z}_{i j}^{\prime} \boldsymbol{\beta}+\delta P T A_{i j}+\alpha_{i}+\gamma_{j}\right) \boldsymbol{\varepsilon}_{i j},
$$

where $\boldsymbol{Z}_{i j}=\left(1, \log D I S T_{i j}, B O R D_{i j}, \ldots\right)^{\prime}$ is a vector collecting all exogenous variables besides $P T A_{i j}$, and $\boldsymbol{\beta}=\left(\beta_{0}, \beta_{1}, \beta_{2}, \ldots\right)^{\prime}$ is the corresponding parameter vector. $\alpha_{i}=$ $\ln \left(y_{i} \Pi_{i}^{\sigma-1}\right)$ and $\gamma_{j}=\ln \left(y_{j} P_{j}^{\sigma-1}\right)$, which can be controlled for by including importerand exporter fixed effects. $\delta$ is the coefficient of interest for the PTA, and $\boldsymbol{\varepsilon}_{i j}$ is a remainder error term.

Many countries in our sample do not trade with all potential trade partners. While zero trade flows are not per se a problem for our multiplicative specification (see Santos Silva and Tenreyro, 2010, 2011), one may believe that the decision to start exporting with a country (the extensive margin) follows a different process than the decision how much to trade with a given trade partner (the intensive margin).

ELSW show how one can disentangle the conditional expectation of the bilateral trade flows $\mathbb{E}\left(X_{i j} \mid\right.$.) into the expectation of the value of positive trade flows (the intensive margin) and the probability that two countries trade with each other at all (the extensive margin). Taking expectations and using the law of iterated expectations, one obtains:

$$
\begin{aligned}
\mathbb{E}\left[X_{i j} \mid .\right]=\operatorname{Pr}\left[\mathbb{I}_{i j}\right. & =1 \mid .] \mathbb{E}\left[\exp \left(\boldsymbol{Z}_{i j}^{\prime} \boldsymbol{\beta}+\delta P T A_{i j}+\alpha_{i}+\gamma_{j}\right) \boldsymbol{\varepsilon}_{i j} \mid ., \mathbb{I}_{i j}=1\right] \\
& =\operatorname{Pr}\left[\mathbb{I}_{i j}=1 \mid .\right] \mathbb{E}\left[X_{i j} \mid ., \mathbb{I}_{i j}=1\right] .
\end{aligned}
$$

It follows that the intensive and extensive margins can be estimated separately.

The positive part of exports, $\mathbb{E}\left[X_{i j} \mid ., \mathbb{I}_{i j}=1\right]$, is estimated via a gravity equation following Santos Silva and Tenreyro (2006). This accounts for recent developments in the gravity literature that estimates the trade equation multiplicatively to deal with the 
potential heteroskedasticity of trade flows. Being closely related to the theoretical derivations of the gravity equation and estimating the parameters structurally has several advantages. Specifically, we can handle general equilibrium effects, which are crucial for policy evaluations at the country level. ${ }^{9}$ Compared to computable general equilibrium models (CGE models), this approach has the additional advantage that the estimated parameters are obtained from the same data as the counterfactual analysis is based on.

Following Egger and Larch (2011) and ELSW, the extensive margin, $\operatorname{Pr}\left[\mathbb{I}_{i j}=1 \mid\right.$. ], is estimated via a probit model. We specify the following model for selection into exporting:

$$
\begin{gathered}
\mathbb{I}_{i j}=1 \text { if } \boldsymbol{Q}_{i j}^{\prime} \mathbf{w}+\kappa P T A_{i j} \geq \boldsymbol{\xi}_{i j}, \\
\mathbb{I}_{i j}=0 \text { else }
\end{gathered}
$$

where the vector $\boldsymbol{Q}_{i j}$ is a set of exogenous variables which determine whether trade flows are positive, $\mathbf{w}$ is the corresponding parameter vector, $\kappa$ is the parameter of $P T A_{i j}$, and $\boldsymbol{\zeta}_{i j}$ is a stochastic error term. $\boldsymbol{Q}_{i j}$ will contain the same elements as $\boldsymbol{Z}_{i j}$, but the estimated parameter vectors will differ.

For the proper evaluation of the membership in a free trade agreement it is not only important to obtain consistent estimates of trade costs (which give the direct, partial effect of trade agreement membership on trade flows), but also to account for the general equilibrium effects of trade agreements, i.e., changes in multilateral resistance terms as well as GDPs (see Anderson and van Wincoop (2003), Appendix B). Therefore, it is necessary to perform a counterfactual analysis which calculates the unobserved counterfactual situation with a TTIP in place.

We do this by using the underlying structure of the model. Relying on the parameter estimates, we use the model equations and calculate the situation with and without a TTIP taking into account trade diversion and income effects, as well as potential changes at the extensive and intensive margin (see for details Egger and Larch, 2011).

Summarizing, our quantitative strategy consists of six steps:

1. Estimate parameters of (7) based on observed bilateral trade flows, i.e., we estimate a probit model for the extensive margin and a Poisson Pseudo Maximum Likelihood (PPML) model for the intensive margin.

2. Use these estimates and observed GDPs to solve the system of equations for the MRTs for all countries given in equation (3) in the baseline.

3. Switch the PTA dummy from zero to one for pairs covered by a new trade agreement (e.g., EU-US pairs for a TTIP).

4. Calculate counterfactual vectors of MRTs, taking into account the changes in GDPs brought about by trade cost changes (see Anderson and van Wincoop, 2003, Appendix B).

\footnotetext{
${ }^{9}$ Heckman, Lochner and Taber (1998, S.381) argue that standard approaches for the evaluation of policies are misleading if individual decisions affect the decisions of other individuals (in our case: trade partners). The empirical treatment evaluation literature usually assumes that there are no general equilibrium effects. This makes it less suitable for the evaluation of large scale policies such as trade agreements where general equilibrium effects are crucial and potentially important.
} 
5. Calculate counterfactual predictions of the extensive margin using the probit.

6. Use the counterfactual extensive margin predictions as well as the counterfactual MRT terms and the counterfactual GDPs to calculate the changes in trade flows and welfare (i.e., real GDP per capita). Welfare changes are calculated as

$$
\widehat{\mathrm{W}}_{\mathrm{i}}=\left[\left(\frac{\mathrm{y}_{\mathrm{i}} / \mathrm{y}_{\mathrm{W}}}{\mathrm{y}_{\mathrm{c}, \mathrm{j}} / \mathrm{y}_{\mathrm{c}, \mathrm{W}}}\right)^{1 /(1-\sigma)}\left(\frac{\Pi_{\mathrm{c}, \mathrm{i}} \mathrm{P}_{\mathrm{c}, \mathrm{i}}}{\Pi_{\mathrm{i}} \mathrm{P}_{\mathrm{i}}}\right)-1\right] \times 100[\%],
$$

where $\mathrm{c}$ denotes the counterfactual scenario (see Egger and Larch, 2011, eqn. (12)).

In the counterfactual scenario, we keep the size of the population constant, so that the change in real GDP is equal to the change in real GDP per capita. Also, note that the single sector nature of our model implies that changes in real GDP can be interpreted as an equivalent variation (EV) measure. Finally, since the econometric estimates identify the long-run effects of PTAs, our results are to be interpreted as pertaining to the longrun as well. Virtually the entire effect is materialized after 10 to 15 years; see Baier and Bergstrand (2007) or Anderson and Yotov (2011).

\subsection{Estimating the treatment effect of PTAs}

The PTA coefficient can be interpreted as the local, partial equilibrium, average treatment effect of a free trade agreement on trade flows. One main challenge in its estimation is the non-random selection of country pairs into trade agreements. For example, country size and distance between countries are important explanatory factors for PTA membership (see, e.g., Baier and Bergstrand (2004). Failing to account for the endogeneity of PTA membership is likely to yield downward biased coefficients; see Baier and Bergstrand (2007, p. 78). If the error term in the gravity model represents unobservable policy-related barriers that reduce trade, and if those barriers make a PTA more likely, then the PTA dummy and the error term will be negatively correlated, leading to underestimation of the PTA coefficient. The literature has found this problem to be relatively severe.

Baier and Bergstrand (2002) use treatment estimators to evaluate the effect of PTAs on trade flows and find that, on average, when acknowledging the endogeneity of a PTA, the agreement tends to increase the value of trade by 92 percent. They also show that estimates for specific agreements differ widely. Magee (2003) uses panel data and finds trade effects of PTAs of 45 percent when using OLS, and effects up to 800 percent when accounting for the potential endogeneity of PTAs. Baier and Bergstrand (2007) also use panel estimators and show that a PTA will increase two member countries' trade by about 100 percent after 10 years, seven times the 14 percent increase effect estimated when ignoring endogeneity. Egger and Larch (2011) follow their approach but explicitly model the extensive margin using panel data. Their estimates imply that European Agreements have increased bilateral trade flows among members by about 96 percent. Baier and Bergstrand (2009) use a matching estimator and panel data and find an average long-run effect of a PTA of 100 percent. They also show that effects differ substantially across trade agreements. ELSW develop a two-part model accounting for 
the potential simultaneous endogeneity of PTAs and positive trade flows for a crosssection of countries. Their identification strategy relies on the availability of suitable instruments. They find an average treatment effect of PTAs on bilateral trade flows of 236 percent.

Our approach tries to tackle the endogeneity of the PTA dummy while retaining the largest possible sample size and using the most recent data available. A panel for a large cross-section of countries is hard to handle due to data-constraints and computational difficulties resulting from the high number of fixed effects. Therefore, we opt for a more agnostic approach and estimate our model on a cross-section for 173 countries for the year 2012, constraining the PTA coefficients to the estimate from ELSW as a baseline scenario. Acknowledging the large dispersion of estimated PTA coefficients, we conduct numerous sensitivity analyses

\section{DATA AND PARAMETER ESTIMATES}

\subsection{Data}

We work with data for 173 countries dating from the year 2012. Table 2 provides summary statistics. As usual, the distribution of exports is extremely skewed: the mean value of exports is 545 while the median is only 0.24 . The sample includes all preferential trade agreements notified to the WTO that are active since 2012 and earlier. The data are augmented and corrected by using information from PTA secretariat web pages. In total, we cover about 300 agreements. Many of these agreements are pure bilaterals, so that only about $17 \%$ of the 29,756 country pairs in our analysis are affected by a PTA. ${ }^{10}$ Tariff data is available only for a smaller sample $(\mathrm{C}=146)$; for details see Table A2 in the Web Appendix.

Table 2. Summary statistics (year 2012, C=173)

\begin{tabular}{lrrrrr}
\hline \hline & Mean & p50 & Std.dev. & min & Max \\
\hline Exports (mn USD), X & 545.44 & 0.24 & 5862.42 & 0.00 & 444407.20 \\
Active exports, dummy (0,1), II & 0.72 & 1.00 & 0.45 & 0.00 & 1.00 \\
PTA, dummy (0,1), PT A & 0.17 & 0.00 & 0.38 & 0.00 & 1.00 \\
Geographical distance, logDIST & 8.78 & 8.95 & 0.76 & 4.11 & 9.89 \\
Contiguity, dummy (0,1), BORD & 0.02 & 0.00 & 0.13 & 0.00 & 1.00 \\
Common language, dummy (0,1), LANG & 0.15 & 0.00 & 0.35 & 0.00 & 1.00 \\
Common colonizer, dummy (0,1), COLONY & 0.10 & 0.00 & 0.31 & 0.00 & 1.00 \\
\hline Tariff (\%) & 7.43 & 7.14 & 5.48 & 0.00 & 33.36 \\
\hline Number of observations & 29,756 & & & & \\
\hline
\end{tabular}

Notes: The trade data come from UN Comtrade and refer to the year of 2012. The PTA dummy takes value one if a regional trade agreement between two countries has been notified to the WTO. The other variables are from CEPII. " Tariff data is only available for a subsample of 146 countries (21,170 country pairs); see the Web Appendix Table A2 for details.

\footnotetext{
${ }^{10}$ The PTA data is available on hTPP://www.ewf.uni-bayreuth.de/en/research/index.html.
} 
The other variables include the log of geographical distance, a dummy indicating a common border between two countries (i.e., their contiguity), a dummy for common language and one for a common colonizer. All these variables are taken from the gravity data set provided by CEPII in Paris.

\subsection{Parameter Estimates}

Table 3 reports the parameter estimates that we use in our quantitative exercise. We report results from a two-stage model; results for the model without selection are available in the Web Appendix. We distinguish four specifications of the trade cost function. Column [1] refers to our preferred model, where the PTA effect is taken from ELSW, while the other coefficients are estimated on our 2012 data using the procedure described in Section 3 conditional on the PTA coefficient. This procedure makes sure that we fit the model to the 2012 base line data while accounting for the potential endogeneity of PTAs. Column [2] reports the parameters of the trade cost function as reported in the meta study of structural gravity equations conducted by Head and Mayer (2014). In the sample that underlies this meta study, almost no paper controls for the endogeneity of PTAs and, thus, the point estimate on the PTA dummy is very different from the one used in [1]. Column [3] is a specification which makes sure that the welfare effect for the US obtained from our model is identical to the one calculated by FMNPT. Specification [4] is identical to [1], but utilizes the smaller sample for which tariff data is available (and where we include the tariff factor $\left(1+\tau_{i j}\right)$ to the power of the appropriate elasticity $(-\sigma)$, which we take to be equal to -8 in our benchmark case). Columns [5] and [6] report the selection equations associated to models [1] to [4]; again, the coefficient of the PTA dummy has been taken from ELSW, so that we are sure to avoid a bias due to endogeneity. In all equations, we include a full array of exporter and importer fixed effects. Table 3 shows that the model fits the baseline data very well. We explain about $93 \%$ of the variation in trade flows. 
Table 3. Parameters of the trade cost function (two stage models)

\begin{tabular}{|c|c|c|c|c|c|c|}
\hline & \multicolumn{4}{|c|}{ Intensive margin } & \multicolumn{2}{|c|}{ Selection equation } \\
\hline & $\begin{array}{c}{[1]} \\
\text { Preferred }\end{array}$ & $\begin{array}{c}{[2]} \\
\text { HM }\end{array}$ & $\begin{array}{c}{[3]} \\
\text { FMNPT }\end{array}$ & $\begin{array}{c}{[4]} \\
\text { Tariffs } \\
\text { only }\end{array}$ & $\begin{array}{c}{[5]} \\
\operatorname{ad}[1]-[3]\end{array}$ & $\begin{array}{c}{[6]} \\
\operatorname{ad}[4]\end{array}$ \\
\hline PTA & 1.21 & 0.36 & 0.12 & 1.21 & 0.00 & 0.00 \\
\hline $\log$ DIST & $\begin{array}{c}\cdot \\
-0.50 \\
(0.03)\end{array}$ & -1.10 & $\begin{array}{c}\cdot \\
-0.50 \\
(0.03)\end{array}$ & $\begin{array}{c}\cdot \\
-0.49 \\
(0.03)\end{array}$ & $\begin{array}{c}\cdot \\
-0.79 \\
(0.03)\end{array}$ & $\begin{array}{l}\cdot \\
-0.81 \\
(0.03)\end{array}$ \\
\hline BORD & $\begin{array}{c}0.20 \\
(0.08)\end{array}$ & 0.66 & $\begin{array}{c}0.20 \\
(0.08)\end{array}$ & $\begin{array}{c}0.20 \\
(0.08)\end{array}$ & $\begin{array}{l}-0.64 \\
(0.16)\end{array}$ & $\begin{array}{l}-0.12 \\
(0.2)\end{array}$ \\
\hline LANG & $\begin{array}{c}0.19 \\
(0.08)\end{array}$ & 0.39 & $\begin{array}{c}0.19 \\
(0.08)\end{array}$ & $\begin{array}{c}0.20 \\
(0.09)\end{array}$ & $\begin{array}{c}0.16 \\
(0.05)\end{array}$ & $\begin{array}{c}0.20 \\
(0.07)\end{array}$ \\
\hline COLONY & $\begin{array}{c}0.71 \\
(0.17)\end{array}$ & 0.75 & $\begin{array}{c}0.71 \\
(0.17)\end{array}$ & $\begin{array}{c}0.76 \\
(0.18)\end{array}$ & $\begin{array}{c}0.36 \\
(0.05)\end{array}$ & $\begin{array}{c}0.33 \\
(0.06)\end{array}$ \\
\hline Pseudo $R^{2}$ & 0.93 & & & & & \\
\hline
\end{tabular}

Notes: Number of countries C=173; number of observations N=29,756. "Preferred" refers to a specification which accounts for the potential endogeneity of RTAs, with the point estimate taken from Egger, Larch, Staub and Winkelmann (2011). "HM" reproduces the estimates reported in the metaanalysis of Head and Mayer (2014). "FMNPT" uses the benchmark estimates from [1] but uses that value of the PTA coefficient that is necessary to replicate the EV measure for the US as predicted by Francois, Manchin, Norberg, Pindyuk and Tomberger (2013, FMNPT). "Tariffs only" is the same specification as [1] but is based on a smaller country sample $(\mathrm{C}=146, \mathrm{~N}=21,170)$ due to the limited availability of tariff data. All specifications contain two separate arrays of exporter and importer fixed effects. Robust standard errors for the estimated coefficients are in parenthesis. When we fix coefficients at values from other studies, we do not provide standard errors, which is denoted by a dot.

\section{THE WELFARE EFFECTS OF A TTIP}

\subsection{Potential gains with different trade cost functions}

We are now ready to simulate counterfactual scenarios. We set the PTA dummy to unity in all country pairs that involve the US or EU Member states and calculate the resulting equilibrium vector of GDPs and price levels. We compute the difference between counterfactual real per capita incomes and the observed baseline outcomes for 2012.

Table 4 reports unweighted, GDP-weighted and population weighted summary statistics for the welfare estimates resulting from different specifications of our model. Starting with our preferred specification [1], a model that allows for selection, we find that the effect of introducing a TTIP leaves the average country unaffected, but the standard deviation is relatively high (1.9\%). The GDP-weighted summary statistics look different: the average country now gains $1.6 \%$, and the standard deviation has gone up to 
2.8. This implies that a TTIP increases world GDP, but its positive effect is concentrated in countries that are relatively rich to start with (EU and US). Finally, populationweighted summary statistics also report a mean effect of zero: i.e., the average individual on the planet remains unaffected by a TTIP. The largest beneficiary of a TTIP registers an increase in real GDP per capita of 5.6\% (Spain), the country worst affected finds its real GDP per capita go down by $3.1 \%$ (Canada) (see Table 5).

Table 4. Benchmark welfare effects (in \%) and the roles of selection and PTA point estimates: Summary statistics

\begin{tabular}{|c|c|c|c|c|c|c|c|c|c|}
\hline & & \multicolumn{2}{|c|}{ unweighted } & \multicolumn{2}{|c|}{$\begin{array}{c}\text { GDP- } \\
\text { weighted }\end{array}$} & \multicolumn{2}{|c|}{$\begin{array}{c}\text { POP- } \\
\text { weighted }\end{array}$} & \multirow[b]{2}{*}{ Min } & \multirow[b]{2}{*}{ Max } \\
\hline \multicolumn{2}{|c|}{ Specifications } & Mean & $\begin{array}{l}\text { Std. } \\
\text { Dev. }\end{array}$ & Mean & $\begin{array}{l}\text { Std. } \\
\text { Dev. }\end{array}$ & Mean & $\begin{array}{l}\text { Std. } \\
\text { Dev. }\end{array}$ & & \\
\hline \multicolumn{10}{|c|}{ Models with selection } \\
\hline [1] & Preferred & -0.04 & 1.93 & 1.58 & 2.78 & -0.01 & 1.73 & -3.09 & 5.56 \\
\hline [2] & HM & 0.01 & 0.27 & 0.21 & 0.36 & 0.01 & 0.23 & -0.44 & 1.13 \\
\hline [3] & FMNPT & -0.01 & 0.17 & 0.13 & 0.23 & -0.02 & 0.15 & -0.18 & 0.49 \\
\hline [4] & Tariffs only & -0.01 & 0.18 & 0.13 & 0.23 & 0.00 & 0.15 & -0.27 & 0.48 \\
\hline \multicolumn{10}{|c|}{ Models without selection } \\
\hline$\left[\mathbf{1}^{\prime}\right]$ & Preferred & -0.23 & 1.96 & 1.58 & 2.78 & -0.03 & 1.73 & -3.10 & 5.53 \\
\hline [2'] & HM & -0.01 & 0.28 & 0.21 & 0.36 & 0.01 & 0.23 & -0.44 & 1.13 \\
\hline$\left[3^{\prime}\right]$ & FMNPT & -0.02 & 0.18 & 0.13 & 0.23 & -0.02 & 0.15 & -0.18 & 0.49 \\
\hline [4'] & Tariffs only & -0.02 & 0.18 & 0.13 & 0.23 & 0.00 & 0.15 & -0.27 & 0.48 \\
\hline
\end{tabular}

Source: Authors' calculations.

Note. All specifications set $\varepsilon=7.173$ countries. Trade cost equations as in Table 3. Welfare change is measured as equivalent variation in $\%$ of initial income. Refer to notes on Table 3 for further detail.

Note that these effects are ceteris paribus changes: nothing else changes except the introduction of a TTIP. Hence, all changes relative to the base line of 2012 are causally attributable to the agreement, and are not driven by assumptions on, say, changes in GDPs for reasons different than a TTIP, or the introduction of other trade agreements (e.g., the Comprehensive Economic and Trade Agreement (CETA) between Canada and the EU or any other agreements currently under negotiation). Clearly, higher GDP growth rates in emerging and developing markets, and the formation of other PTAs, will tend to attenuate the negative effects of a TTIP on third countries.

Deactivating the selection channel (lower panel of Table 4) leads to more dispersion on unweighted welfare effects, but otherwise does not significantly alter the summary statistics of welfare effects relative to the benchmark case. It seems that the effect of a TTIP will be predominantly on the intensive margin.

In contrast, using an alternative trade cost function has major effects. The scenario marked by HM (model [2]) employs the trade cost function that arises from the meta 
analysis of structural gravity equations reported by Head and Mayer (2014). Here, the trade cost reducing effect of trade agreements (and, hence, of a TTIP) is much lower. With our choice of trade elasticity $(\varepsilon=7)$, the point estimate of 0.36 implies a trade cost reduction of approximately 5 percentage points. Importantly, this estimate cannot be interpreted as a causal effect due to the potential endogeneity issue of the PTA dummy. It is to be contrasted to the 17 percentage point reduction that is implied by the estimates of ELSW in their analysis. With the HM assumption, the unweighted average welfare gain remains at $0 \%$, but it falls to $0.2 \%$ when GDP weighting is applied.

When we chose the trade cost reducing potential of PTAs to be consistent with the welfare gains from a TTIP reported by FMNPT (2013) for the US $(0.39 \%)$, we need a PTA coefficient of 0.12 , or, with $(\varepsilon=7)$, a trade cost reduction of 1.7 percent. This assumption reduces average (GDP weighted) welfare gains to $0.1 \%$, with the largest gain $(0.5 \%)$ and the largest loss $(-0.2 \%)$ still accruing to Spain and Canada, respectively; see model [3]. These scenarios assume that the introduction of a TTIP lowers tariff and nontariff barriers. In model [4], we assume that only tariffs are eliminated. This leads to very low average welfare effects.

Table 5 provides detailed information for all EU 28 countries, for NAFTA members (USA, Canada, Mexico), for the BRICS (Brazil, Russia, India, China, South Africa) and for several other countries (Australia, Japan, Norway, and Turkey) which play important roles for either EU or US trade policy.

We already stressed that the results from our static model have to be interpreted as long-run effects. However, our ceteris paribus assumption does not account for any additional dynamic effects. In a recent working paper, Anderson, Larch and Yotov (2014b) investigated the growth effects of TTIP based on the dynamic structural trade model developed by Anderson, Larch and Yotov (2014a). This framework models the inter-temporal consumption-investment choice and endogenizes capital accumulation. In the analysis of Anderson, Larch and Yotov (2014b), TTIP influences this trade-off and triggers additional dynamic effects. Compared to the effects of a static general equilibrium framework, the dynamic channel increases the gains for TTIP insiders by about 25 percentage points and mitigates the negative trade diversion effects for nonmembers. For some outsiders (such as Korea and Singapore), TTIP can even yield positive long-run effects on trade flows. ${ }^{11}$ We may therefore conclude that our static framework may underestimate the average trade and welfare effects of TTIP by neglecting additional positive dynamic effects.

\footnotetext{
${ }^{11}$ Jonathan Eaton and Samuel Kortum study in a series of papers the link between trade, production and growth focussing on technology spill-overs between countries (see for a very good summary with references to all the papers Eaton and Kortum, 2005). Typically, accounting for technological spill-overs opens up an additional channel through which opening up to trade potentially increases welfare. This is also in line with the findings of Grossman and Helpman (1991), who theoretically investigate the role of technology spill-overs focussing on the creation of new products in dynamic multi-country models. To the best of our knowledge, no evaluation of TTIP using a framework along these lines is available up to now.
} 
Table 5. Welfare effects: Selected countries and scenarios

\begin{tabular}{|c|c|c|c|c|c|c|c|}
\hline & & $\begin{array}{c}1] \\
\text { Preferred }\end{array}$ & $\begin{array}{c}{[2]} \\
\text { Pref., w/o } \\
\text { selection }\end{array}$ & [3] & FMNPT & $\begin{array}{c}5] \\
\text { Tariffs } \\
\text { only }\end{array}$ & $\begin{array}{c}\text { [6] } \\
\text { Spillovers }\end{array}$ \\
\hline 1 & Austria & 2.83 & 2.83 & 0.23 & 0.29 & 0.22 & 4.73 \\
\hline 2 & Belgium & 2.25 & 2.25 & 0.09 & 0.25 & 0.17 & 4.12 \\
\hline 3 & Bulgaria & 3.94 & 3.95 & 0.55 & 0.37 & 0.33 & 5.90 \\
\hline 4 & Croatia & 3.53 & 3.53 & 0.50 & 0.34 & 0.38 & 5.49 \\
\hline 5 & Cyprus & 4.36 & 4.36 & 0.68 & 0.39 & 0.37 & 6.33 \\
\hline 6 & Czech Republic & 3.04 & 3.04 & 0.31 & 0.31 & 0.24 & 4.96 \\
\hline 7 & Denmark & 3.45 & 3.45 & 0.43 & 0.34 & 0.28 & 5.38 \\
\hline 8 & Estonia & 4.31 & 4.30 & 0.73 & 0.40 & 0.36 & 6.29 \\
\hline 9 & Finland & 4.60 & 4.60 & 0.77 & 0.42 & 0.39 & 6.58 \\
\hline 10 & France & 3.46 & 3.47 & 0.33 & 0.32 & 0.28 & 5.32 \\
\hline 11 & Germany & 3.48 & 3.49 & 0.33 & 0.30 & 0.28 & 5.28 \\
\hline 12 & Greece & 4.21 & 4.21 & 0.63 & 0.39 & 0.35 & 6.17 \\
\hline 13 & Hungary & 3.50 & 3.49 & 0.44 & 0.34 & 0.28 & 5.44 \\
\hline 14 & Ireland & 4.70 & 4.68 & 0.64 & 0.46 & 0.39 & 6.70 \\
\hline 15 & Italy & 3.86 & 3.85 & 0.50 & 0.34 & 0.32 & 5.74 \\
\hline 16 & Latvia & 4.10 & 4.09 & 0.65 & 0.39 & 0.34 & 6.09 \\
\hline 17 & Lithuania & 3.97 & 3.96 & 0.61 & 0.38 & 0.33 & 5.94 \\
\hline 18 & Luxembourg & 2.57 & 2.57 & 0.19 & 0.28 & 0.20 & 4.48 \\
\hline 19 & Malta & 4.84 & 4.82 & 0.96 & 0.44 & 0.41 & 6.86 \\
\hline 20 & Netherlands & 2.85 & 2.83 & 0.22 & 0.29 & 0.22 & 4.73 \\
\hline 21 & Poland & 3.51 & 3.51 & 0.45 & 0.34 & 0.28 & 5.44 \\
\hline 22 & Portugal & 4.80 & 4.81 & 0.79 & 0.45 & 0.40 & 6.80 \\
\hline 23 & Romania & 3.87 & 3.87 & 0.65 & 0.38 & n.a. & 5.82 \\
\hline 24 & Slovak Rep. & 3.40 & 3.40 & 0.41 & 0.34 & 0.27 & 5.34 \\
\hline 25 & Slovenia & 3.14 & 3.14 & 0.32 & 0.32 & 0.25 & 5.06 \\
\hline 26 & Spain & 5.56 & 5.53 & 1.13 & 0.49 & 0.48 & 7.55 \\
\hline 27 & Sweden & 4.25 & 4.24 & 0.71 & 0.39 & 0.35 & 6.20 \\
\hline 28 & United Kingdom & 5.14 & 5.11 & 0.80 & 0.43 & 0.44 & 7.05 \\
\hline \multicolumn{2}{|c|}{ EU average } & 3.94 & 3.93 & 0.51 & 0.36 & 0.32 & 5.83 \\
\hline 29 & United States & 4.89 & 4.91 & 0.59 & 0.39 & 0.41 & 5.95 \\
\hline 30 & Australia & -2.01 & -2.02 & -0.09 & -0.09 & -0.17 & -0.93 \\
\hline 31 & Brazil & -0.77 & -0.74 & -0.08 & -0.09 & -0.05 & 0.06 \\
\hline 32 & Canada & -3.09 & -3.10 & -0.44 & -0.18 & -0.27 & -1.82 \\
\hline 33 & China & -0.50 & -0.49 & -0.03 & -0.05 & -0.04 & 0.13 \\
\hline 34 & India & -0.31 & -0.30 & -0.05 & -0.07 & -0.03 & 0.65 \\
\hline 35 & Japan & -0.51 & -0.02 & -0.05 & -0.50 & -0.05 & -0.04 \\
\hline 36 & Mexico & -2.56 & -2.57 & -0.41 & -0.17 & -0.22 & -1.37 \\
\hline 37 & Norway & -1.91 & -1.92 & -0.27 & -0.14 & -0.17 & -1.05 \\
\hline 38 & Russian Fed. & -1.01 & -1.02 & -0.12 & -0.10 & -0.08 & -0.16 \\
\hline 39 & South Africa & -1.69 & -1.70 & -0.12 & -0.10 & -0.14 & -0.82 \\
\hline 40 & Turkey & -1.56 & -1.59 & -0.17 & -0.11 & -0.14 & -0.72 \\
\hline \multicolumn{2}{|c|}{ Non-TTIP average } & -0.92 & -0.92 & -0.10 & -0.08 & -0.08 & -0.07 \\
\hline \multicolumn{2}{|c|}{ World average } & 1.58 & 1.58 & 0.21 & 0.13 & 0.13 & 2.73 \\
\hline
\end{tabular}

Source: Authors' calculations. Results on all 173 countries are available in the Appendix, Table A1. No tariff data available for Romania in 2012.

\subsection{Welfare effects in the EU28 under the preferred specification}

Figure 4 looks more closely into the potential welfare effects of a TTIP on EU countries. We report our preferred scenario, as it is the only one that accounts for the endogeneity 
of PTAs. Countries coloured in dark blue register increases of real per capita GDP between $3.6 \%$ and 5.6\%; countries in light blue see increases between $1.5 \%$ and $3.6 \%$. The highest gains are found in Spain (5.6\%), followed by the United Kingdom $(5.1 \%)$ and Ireland (4.7\%). The lowest gains are found in Belgium (2.3\%), Luxembourg $(2.6 \%)$, and Austria (2.8\%).

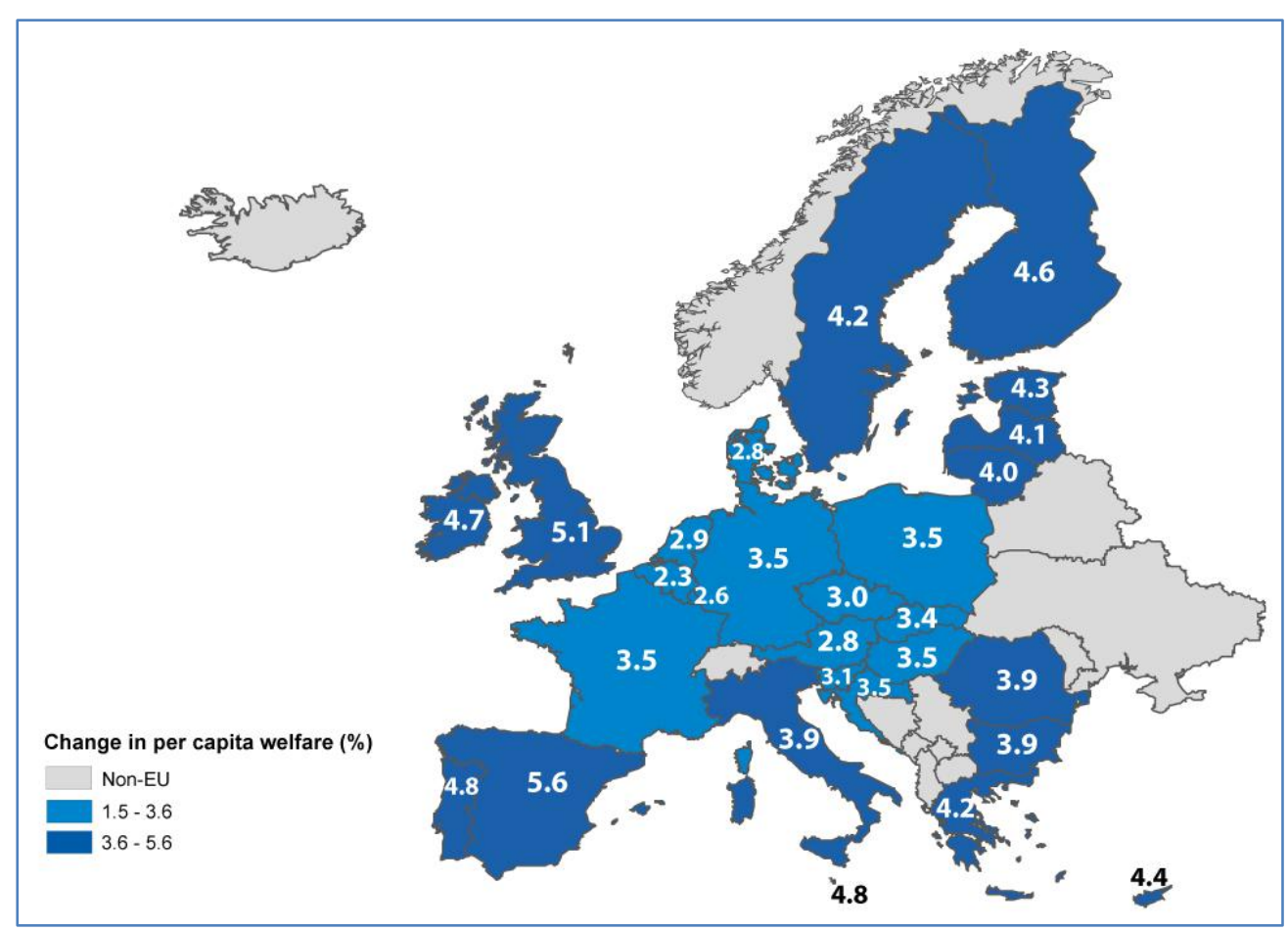

Figure 4. Welfare effects of a TTIP in the EU28

Source: Author's calculations

Notes: Changes in real per capita income in \% from introducing a TTIP. Simulation results refer to our preferred specification.

Figure 5 correlates the welfare gains in the EU28 with two important country characteristics: the baseline level of real per capita GDP (measured in log per capita income in purchasing power parities), and the degree of openness (measured in the fraction of merchandise trade (exports plus imports divided by two) over GDP).

The regression line pictured in the left-hand panel indicates a negative correlation between the welfare gains and base line GDP per capita. The slope $(-0.21)$ is, however, not statistically different from zero at the conventional levels of significance (the robust standard error is 0.21 ). Nonetheless, it is important to notice that a TTIP does not appear to exacerbate real per capita GDP differences within the EU.

The right-hand panel also shows a negative correlation, this time between the welfare gain and base line multilateral openness. Now, the slope of -0.02 is statistically significant (the robust standard error is 0.005 ), and the simple linear model explains 
about a quarter of the variation in welfare gains. The logic for this is clear: countries which are already very open (such as Belgium, Netherlands, or Slovakia) enjoy low average trade costs with the world. Lower trade costs with the US do not unlock large additional gains. In contrast, countries such as Greece, Spain, or Italy appear to have higher multilateral trade costs, and would therefore benefit more from reduced trade costs with the US.
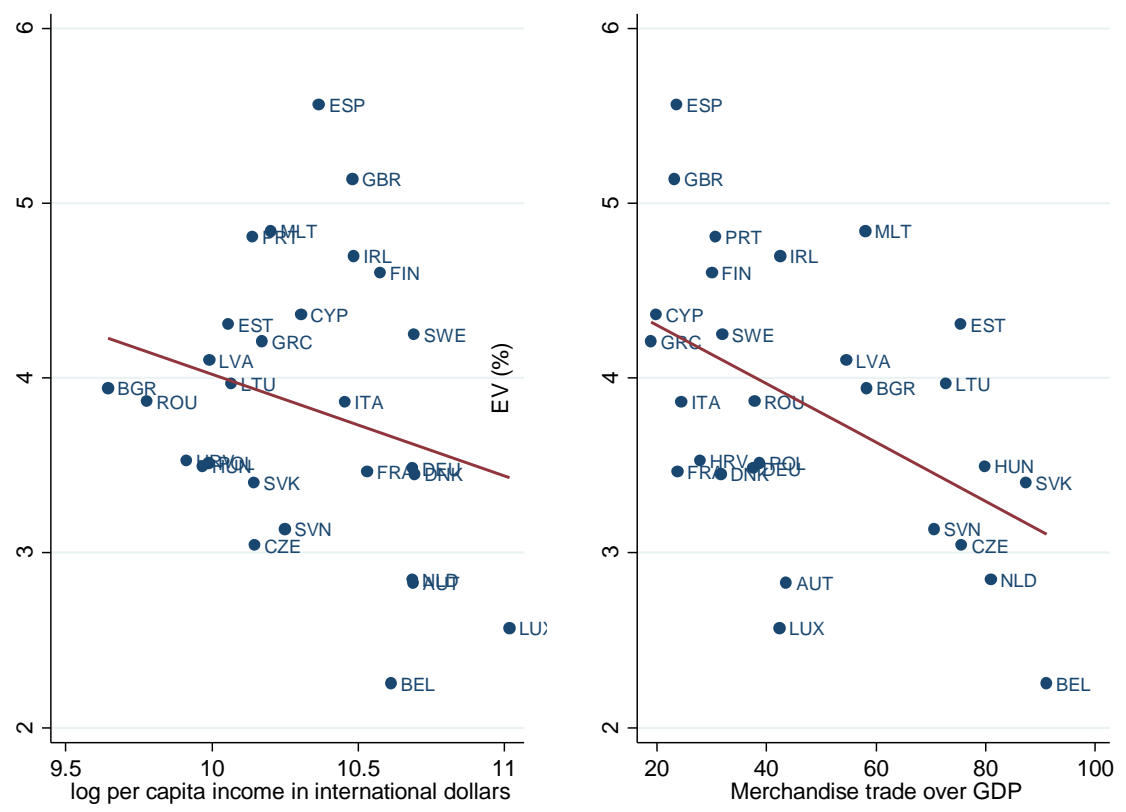

Figure 5. Welfare effects of a TTIP in Europe: Relevant correlations

Source: Authors' calculations based on model predictions and data from the World Bank's WDI data base. All values refer to the year 2012.

GDP per capita and openness are correlated. Putting them together into one regression, we find that the welfare gains are decreased both by baseline openness and initial income. In this multivariate framework, both variables are statistically significant at the $10 \%$ level, and the regression explains about one third of the variance in welfare effects. The results imply that a 10 percentage point increase in openness lowers the expected gain by about 0.2 percentage points. An increase in GDP per capita by $10 \%$ lowers welfare gains by about 0.04 percentage points.

\subsection{Global welfare effects under the preferred specification}

Figure 6 illustrates the potential welfare effects for selected third countries, the EU and the US. Europe gains $3.9 \%$, the US gains $4.9 \%$ (together the TTIP partners increase their real income by $4.4 \%$ ). The US gain more than the EU. This is due to the fact that the EU 
is comprised of 28 separate countries between trade still is hampered by border effects. Hence, the TTIP with the US generates trade diversion effects within Europe which dampen the welfare effects. The US, in contrast, is a homogenous country and is spared these effects. Real world GDP increases by $1.6 \%$, but non-TTIP countries register losses of $-0.9 \%$ on average.

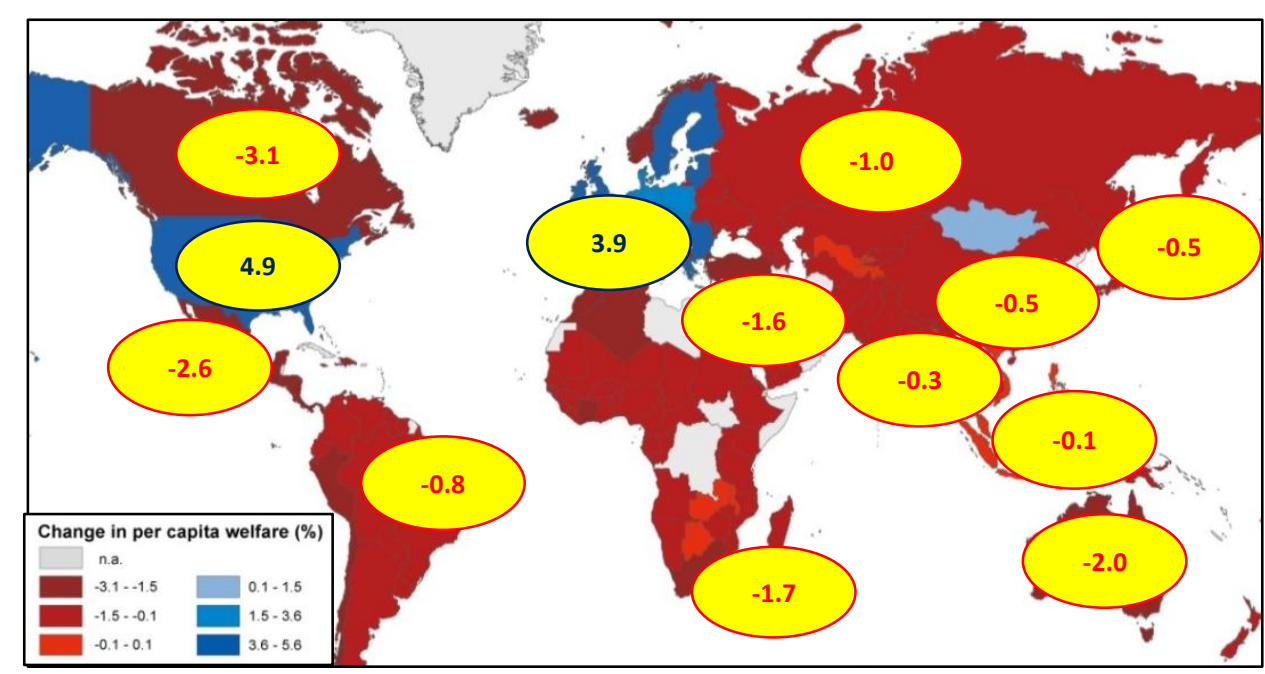

Figure 6. Welfare effects of TTIP in selected countries

Source: Authors' calculations

The figure shows that almost all non-TTIP countries are bound to lose from transatlantic free trade. But, in many large third countries such as China, Japan and India the losses are rather limited.

Figure 7 pictures the frequency distribution of real per capita income changes in our sample of 173 countries. The Figure also provides a kernel density plot. The distribution is bimodal: TTIP countries gain; the average gain is equal to $4.4 \%$. The average welfare effect amongst non-TTIP countries is $-0.9 \%$. The plot shows that most of the 127 countries losing from a TTIP lose only a little: about $25 \%$ of all countries (i.e. 43 countries) lose between 0 and $0.5 \%, 21 \%$ (i.e. 37 countries) lose between 0.5 and $1.0 \%$, and only $8 \%$ of all countries (i.e. 14 countries) lose more than $2.0 \%$.

\subsection{What drives the welfare effects?}

A TTIP would change the structure of world trade. It would lead to trade creation between the EU and the US. It would affect third countries through income and price effects. The latter come in the form of trade diversion and preference erosion. Trade diversion occurs when third countries lose relative competitiveness in the EU and the US, as firms from within the TTIP see their trade costs go down. This loss of market share cannot usually be fully compensated for increased trade with other non-TTIP 
countries. Preference erosion is a problem for countries which enjoy preferential trading conditions with either or both the EU and the US in the 2012 baseline situation. Preference erosion happens within the EU, where a TTIP would dilute the value of the Customs Union and the Single Market. More problematically, it also happens within bilateral agreements that either the EU or the US maintain with third countries. For example, the US has bilateral and plurilateral PTAs with 20 countries: with Canada and Mexico through the North American Free Trade Agreement (NAFTA), with South Korea, Australia, Bahrain, Chile, Colombia, Israel, Jordan, Morocco, Oman, Panama, Peru, Singapore and with 6 smaller Central American countries. The EU has agreements with an even larger number of countries. This list includes countries that also have a PTA with the US, such as Chile, Colombia, Peru, Israel, Jordan, South Korea, Mexico, and Morocco; it includes European countries that are not in the European Union (such as Norway, Iceland, Switzerland, Albania, Serbia); it includes countries in the Middle East and North Africa (such as Algeria, Tunisia, Egypt, and Turkey). Moreover, the EU has a PTA with South Africa.

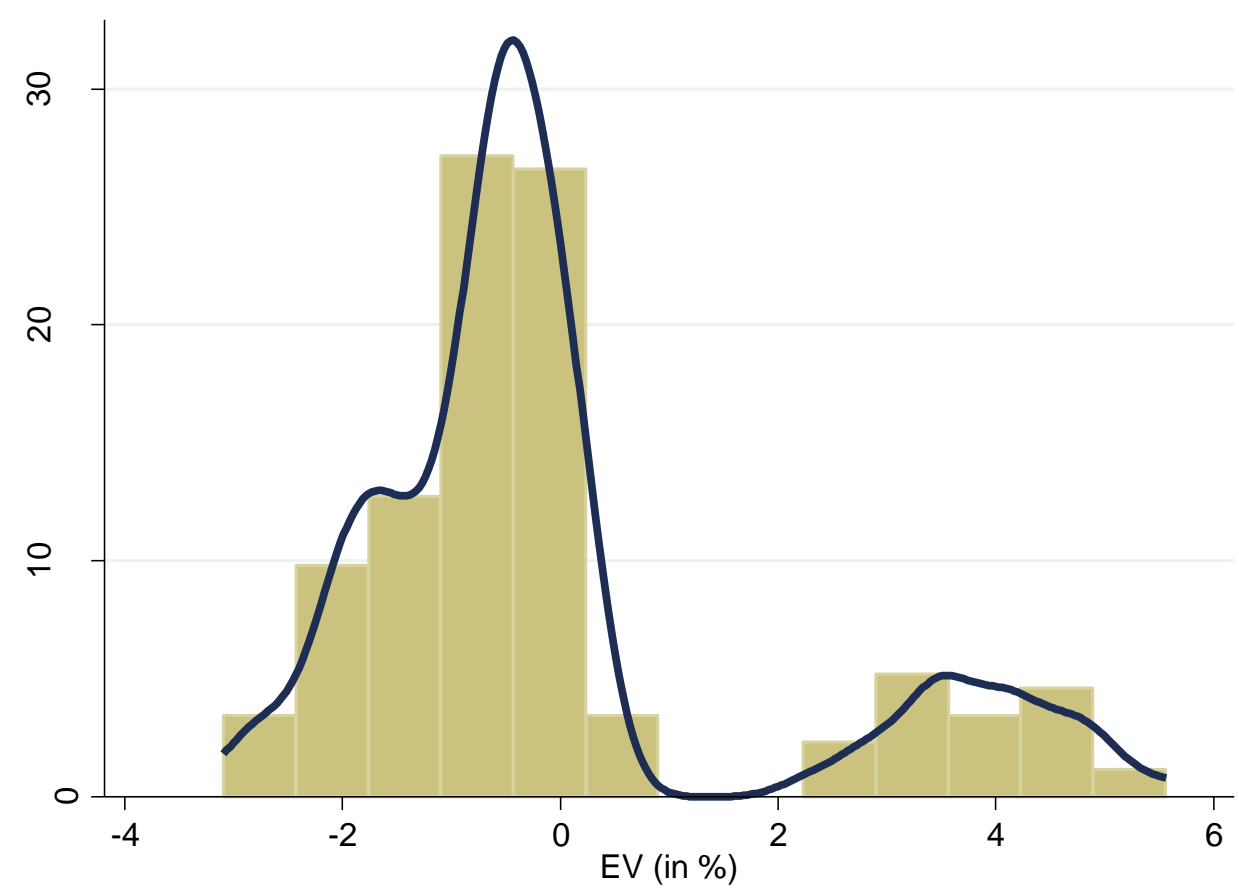

Figure 7. Distribution of welfare gains across countries, preferred scenario

Source: Authors' calculations, frequency distribution.

It is well known that trade diversion and preference erosion may lead to adverse welfare effects from PTAs in third countries. Since the US and the EU are frequently the most important trade partners for the countries with which they entertain PTAs, one has to expect such effects also in the context of a TTIP. 
Multilateral openness, in contrast, attenuates both the negative and the positive effects of a TTIP. Countries that are relatively open in the baseline equilibrium benefit less from bilateral reforms than relatively closed economies, or, conversely, they suffer less when their relative competitiveness in the US or the EU markets deteriorates due to a TTIP. We must therefore expect that typically countries outside the WTO or with low overall trade openness tend to suffer more from a TTIP than countries within the WTO or with high baseline openness.

The 25 countries with the largest losses (ranging from -3.1 to $-1.7 \%$ ) mostly have PTAs with the TTIP members. 20 out of the 25 have a PTA with the EU, 12 with the US, and 10 have PTAs with both the EU and the US. Only 3 countries out of the 25 most strongly hit countries have no PTA with either the EU or the US.

Figure 8 plots the change in per capita real income in \% (equivalent variation, EV) against the change in the share of manufacturing trade (imports plus exports divided by two) over GDP implied by the model. Not surprisingly, there is a strong positive association: both effects are endogenous outcomes driven by the reduction of trade barriers across the Atlantic. Indeed, as known from the work by Arkolakis, Costinot, Rodríguez-Clare (2012), there is a unique non-linear relationship between changes in openness and changes in welfare generated by trade policy reforms. In some cases, the increase in overall openness due to a TTIP is predicted to be quite substantial: Openness in Spain would go up from about $23.6 \%$ to $47.7 \%$, and in the US from about $12 \%$ to $36.9 \%$.

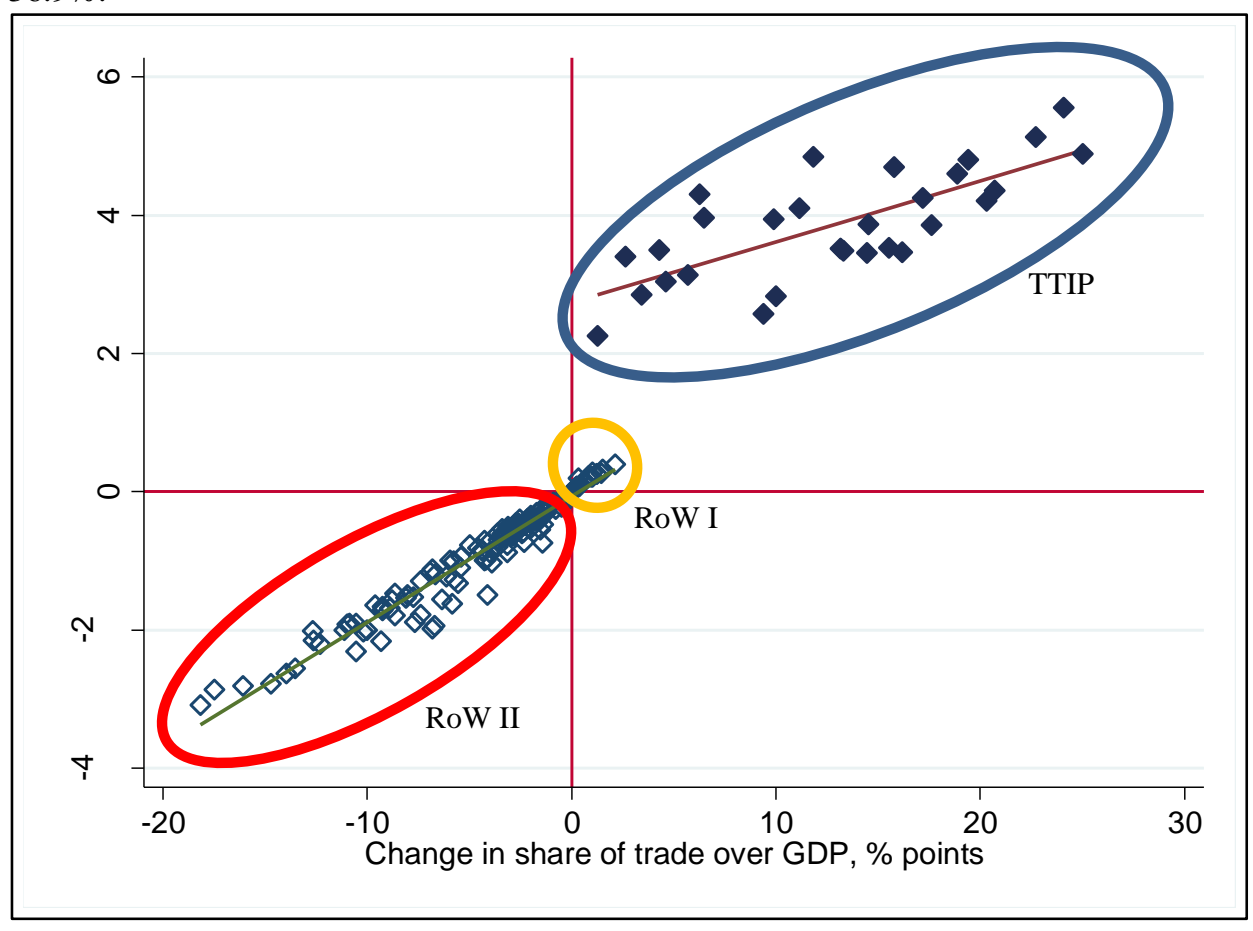

Figure 8. Welfare gains and change in overall openness across countries

Source: Authors' calculations. RoW refers to "rest of the world". 
Figure 8 makes clear that there are three groups of countries: the first is made up by the 29 countries directly involved in a TTIP (EU 28 plus the USA), the second by 17 countries that remain outside of the agreement but whose levels of overall openness and per capita incomes are bound to increase (denoted RoW I), and the third by the 127 countries bound to lose on both measures (RoW II). The non-TTIP countries which benefit are mostly small and poor, and often are island states: Swaziland, Lao PDR, Brunei Darussalam, Lesotho, Palau, Micronesia, Marshall Islands, Tuvalu, Kiribati, Tonga, Solomon Islands, Samoa, Vanuatu, as well as central Asian countries such as Uzbekistan, Bangladesh, Tajikistan, and Mongolia. These countries benefit, because the EU and the US become richer and, therefore, trade more with these 17 economies. This positive effect outweighs the negative trade diversion effect.

In the next step, we investigate the role of multilateral and bilateral openness, as well as per capita income in the baseline situation in shaping the welfare effects of a TTIP in both the group of partner countries and the group of outsiders.

Table 6. Determinants of welfare effects: Conditional correlations

\begin{tabular}{|c|c|c|c|}
\hline \multicolumn{4}{|c|}{ Dep.Var.: Change in real per capita income, EV (\%) } \\
\hline & $(1)$ & (2) & (3) \\
\hline \multirow[t]{2}{*}{ TTIP Dummy $(0,1)$} & $8.57 * * *$ & & $8.54 * * *$ \\
\hline & (2.07) & & (2.09) \\
\hline \multirow{2}{*}{ Openness } & $0.008 * * *$ & & $0.005^{* *}$ \\
\hline & $(0.002)$ & & $(0.002)$ \\
\hline \multirow[t]{2}{*}{ Openness x TTIP } & $-0.03 * * *$ & & $-0.03 * * *$ \\
\hline & $(0.01)$ & & $(0.01)$ \\
\hline \multirow{2}{*}{ ln GDP per capita } & $-0.14 * * *$ & & $-0.09 * * *$ \\
\hline & $(0.01)$ & & $(0.02)$ \\
\hline \multirow[t]{2}{*}{ ln GDP per capita x TTIP } & 0.23 & & -0.28 \\
\hline & $(0.20)$ & & $(0.20)$ \\
\hline \multirow[t]{2}{*}{ PTA with EU } & & $-1.79 * * *$ & $-0.82 * * *$ \\
\hline & & (0.19) & $(0.14)$ \\
\hline \multirow[t]{2}{*}{ PTA with US } & & $-1.05 * * *$ & $-0.70 * * *$ \\
\hline & & $(0.30)$ & $(0.23)$ \\
\hline \multirow[t]{2}{*}{ WTO member } & & $0.60 * * *$ & 0.03 \\
\hline & & $(0.18)$ & $(0.10)$ \\
\hline$R^{2}$ & 0.86 & 0.26 & 0.91 \\
\hline
\end{tabular}

Source: Authors' calculations.

Note: Robust standard errors in parentheses. $* * *, * *$ refer to statistical significance at the $1 \%$ and $5 \%$ levels, respectively. Variables indicated by "x TTIP" refer to interaction terms with the TTIP dummy. Number of observations $=173$. Scenario as in [1] of Table 4 .

Table 6 provides simple conditional correlations in form of linear regressions of welfare effects on country characteristics. Clearly, the relationship between the used variables and the welfare statistic is highly non-linear; however, we feel that our exercise can still reveal interesting patterns. Using the full sample of 173 countries, column (1) in Table 6 shows that a higher degree of multilateral openness (measured, as in Figure 8, by the share of manufacturing trade over 2 times GDP) correlates positively with the 
welfare effects from a TTIP. However, the correlation is negative within the group of TTIP countries. So, countries with high degrees of baseline openness within the TTIP gain less from the initiative, but countries outside the TTIP gain more. This is strongly in line with standard theoretical arguments: the less a country depends on the TTIP partners with its exports or imports, the less it will be hurt by trade diversion effects.

Column (1) also studies the role of baseline real income. A higher initial GDP correlates negatively with the gains from trade, implying that richer countries suffer more from a TTIP, presumably because they trade more strongly with other rich countries such as the US or the EU and are therefore more strongly affected by adverse terms of trade effects. Within the TTIP, however, there is no correlation between initial GDP per capita and the size of the welfare effect.

Column (2) looks at countries' existing trade policies, ignoring the variables studied in column (1). It finds that countries that have a PTA with the EU register average welfare losses of $-1.8 \%$, while countries having PTAs with the US suffer losses averaging $-1.1 \%$. These correlations are conditional on WTO membership, which substantially mitigates negative welfare effects. Note that these policy variables alone explain $26 \%$ of the variation in welfare effects.

Finally, column (3) shows the most comprehensive model. It confirms the insights of columns (1) and (2), except for the role of the WTO: WTO members are substantially more open than (the few) non WTO members in our sample, so that the inclusion of the openness variable absorbs the WTO effect detected in column (2). This simple model explains more than $91 \%$ of the heterogeneity in welfare outcomes in our 173 country sample.

\subsection{Sensitivity Analysis on the Trade Cost Effect of a TTIP}

All scenarios in Table 5 assume that the TTIP would affect trade costs across the Atlantic by the same amount as other agreements have reduced trade costs amongst their members. However, observers of the negotiations disagree on whether TTIP will imply a considerably deeper amount of integration than a typical PTA, or whether TTIP will actually fall short of these expectations as negotiators only agree to abolish NTBs for a very small fraction of traded goods. The question is: How deep and broad will TTIP actually be? Hence, one might want to compare the effect of a TTIP to single, already existing agreements, or to different quantiles of PTAs in terms of their breadth and depth. The obvious problem is that ranking PTAs is difficult, given the different dimensions of breadth and depth (inclusion of agricultural goods, protection of intellectual property rights, inclusion of services trade, different dispute settlement agreements, investor protection etc.). In principle, one could estimate the effect of different types of agreements or even single agreements like NAFTA. However, we 
would still not know which effect to suppose for a TTIP, given its unclear scope. This illustrates the key advantage of assuming it to be average. ${ }^{12}$

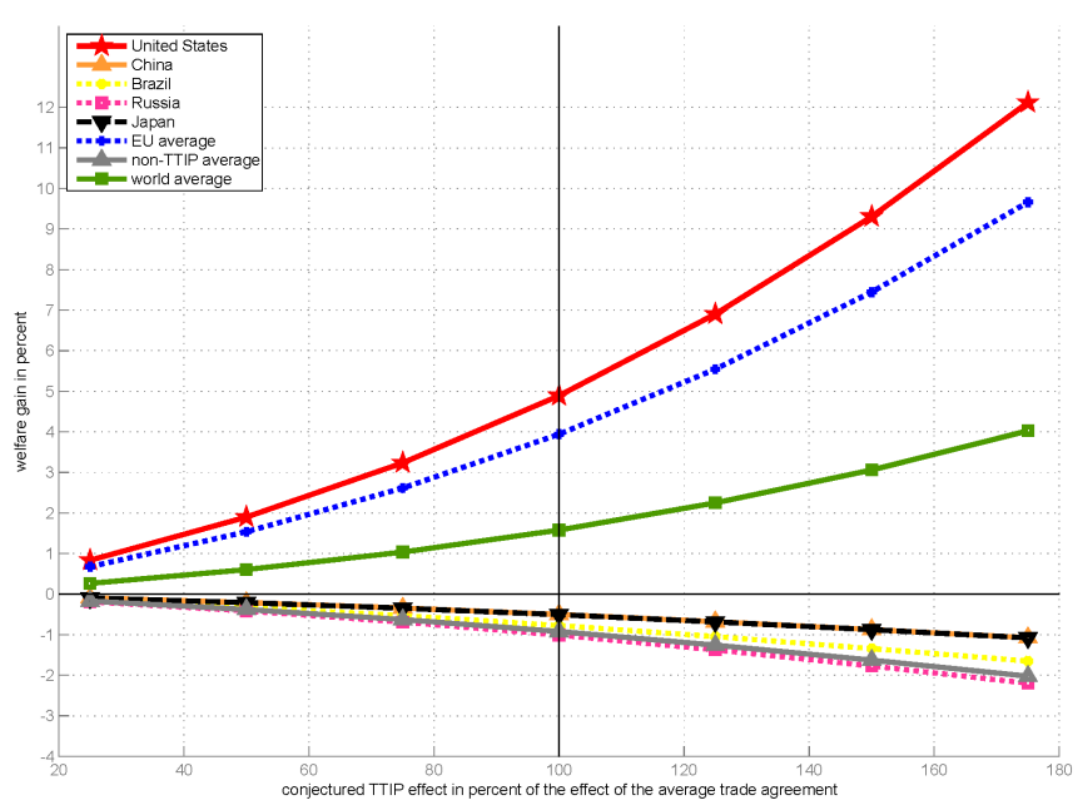

Figure 9. Welfare effects from a TTIP as a function of the depth of the agreement

Nonetheless, to get an idea about the sensitivity of our welfare estimates, we reran our counterfactual simulations of a TTIP by still supposing that existing PTAs have the trade cost reducing effect measured by ELSW but that a TTIP has a lesser or larger effect. We show results for selected countries and regions in Figure 9. The $\mathrm{x}$-axis reports the conjectured effect of a TTIP in percent of the effect of the average PTA. The y-axis presents the associated welfare effect. ${ }^{13}$ As the depth of a TTIP increases, welfare gains for TTIP member countries increase disproportionally, whereas welfare losses for nonmember countries increase, but less so. Hence, the dispersion of the welfare effects goes up in the size of the effect of a TTIP and the scope for redistributive or compensating policies for the countries losing from a TTIP goes up. Also, even if TTIP is much deeper than the average PTA, effects on non-member countries will remain relatively moderate.

Most importantly, Figure 9 effectively traces the policy space for a TTIP and illustrates the sensitivity of our analysis with respect to the conjectured effect of a TTIP. Irrespective of the particular point on the $\mathrm{x}$-axis, the key qualitative welfare results of our study continue to hold: The US has the largest potential benefits, and they get

\footnotetext{
${ }^{12}$ Dür, Baccini, and Elsig (2014) recently developed a dataset containing an index for the depth of agreements. Using this index in the estimation stage would be an alternative way to account for different degrees of integration of PTAs. Still, one would have to assume into which category TTIP will fall.

${ }^{13}$ Effects for regions are GDP-weighted averages of the effects for the individual countries. The full set of welfare changes for all countries for all calculated scenarios is available from the authors upon request.
} 
disproportionally larger the more ambitious the agreed-upon TTIP. Non-member countries mostly have to worry about such a very deep agreement, as a less ambitious TTIP will only have negligible effects on their economies.

\section{SPILL-OVERS AND INTERACTIONS WITH OTHER TRADE AGREEMENTS}

\subsection{Spill-overs: mechanisms and empirical evidence}

So far, we have assumed that a TTIP lowers trade costs only between the EU member states and the US. However, if the agreement lowers trade costs also between TTIP partners and third countries, or even amongst third countries themselves, the negative effects on excluded countries may be attenuated or may even turn positive (Baldwin, 2011). Indeed, one may conjecture that the sheer size of the transatlantic partnership and its focus on regulatory convergence makes the TTIP systemically important so that it creates positive spill-overs for other countries.

The reason is that firms based in non-TTIP countries may benefit from a simplification of either EU or US regulatory requirements. Kox and Lejour (2006) provide evidence that differences in services regulations can increase operating costs in different markets so that harmonizing those rules may result in lower costs for all exporters in a nondiscriminatory fashion.

Citing this reference, FMNPT (2013, p. 28-29) include direct and indirect spill-overs into their analysis. They model direct spill-overs by assuming that improved regulatory conditions negotiated between the EU and the US result in a limited fall in related trade costs for third countries exporting to the EU and US. This means that exporters from third countries enjoy improved access to the EU and US markets. However, there is no reciprocal benefit for EU or US based exporters.

Indirect spill-overs arise if third countries adopt some of the common standards agreed between the EU and the US. This assumes that a TTIP can successfully impose global standards to which third countries also find it optimal to adhere. Then, the transatlantic agreement would give firms from the EU and the US improved access to third markets. In addition, NTMs amongst third countries would also fall as their standards and norms move closer to the common model promoted by a TTIP. Therefore, indirect spill-overs would lead to lower costs and greater trade between third countries as well.

Clearly, such spill-overs would further increase the overall welfare gains from a TTIP and make it much less likely that third countries lose. However, both the theoretical and the empirical underpinnings for spill-overs are weak. This is why we have not allowed for spill-overs in our preferred specification. In the following, we briefly review the literature that supports our case.

On the theory side, authors have long stressed that preferential trade cost reductions are inherently discriminatory. Viner (1950) introduced the terms "trade creation" and "trade diversion" over sixty years ago to highlight the fact that PTAs likely create new trade between member countries partly by diverting trade from non-members countries. 
Panagariya (2000) nicely motivates his discussion of trade diversion and creation by stating: "Any discussion of the welfare effects of PTAs must inevitably begin with the influential concepts of trade creation and diversion."

On the empirical side, let us start by noting that the existence of large and accurately estimated PTA coefficients in gravity equations of international trade implies that spillovers cannot be very large. If it were the case that bilateral trade reform lowers trade costs for all country pairs, one should not be able to detect that trade growth is larger within PTAs than outside. Also, the skepticism which TTIP has met in third countries testifies to the plausibility of adverse trade diversion effects.

There is a large empirical literature that explicitly quantifies trade diversion effects for different preferential trade agreements. While Clausing (2001) finds little evidence for trade diversion for the Canada - United States Free Trade Agreement (CUSPTA) ${ }^{14}$, Trefler (2004) and Romalis (2007) do find evidence for trade diversion for CUSPTA and NAFTA, respectively. While Trefler (2004) finds trade creation does still outweigh trade diversion to ensure that there are welfare gains from NAFTA in Canada, Romalis (2007) concludes that "the more detailed data used in this paper reveals much more substantial trade diversion than Trefler, so much so that there appear to be essentially no welfare gains for any NAFTA member" (page 417). However, Romalis (2007) does not only find no welfare gains for the NAFTA members, but also finds evidence for negative third-country effects for non-NAFTA members. His analysis of trade diversion reveals that a 1 percent drop in intra-North American tariffs leads to about a 2 percent fall in exports from other countries relative to the European Union.

Chang and Winters (2002) analyze the trade diversion effects of non-MERCOSUR exports to Brazil after inception of MERCOSUR. They find strong negative terms-oftrade effects for non-member countries and conclude their analysis with the statement: "Our results give empirical backing to the well-known theoretical argument that even if external tariffs are unchanged by integration, nonmember countries are likely to be hurt by regional integration" (page 901).

The papers cited above discuss the evidence for trade diversion of PTAs in general. We now turn to empirical studies that explicitly deal with the trade diversion effects related to NTM reforms. Chen and Mattoo (2008) use panel data to analyze the effects of PTAs that include mutual recognition agreements (MRAs). They find that while MRAs increase trade between participating countries, the effects on outsiders are less clear cut and crucially depend on the ability of the outside countries to meet standards. As the standards are more likely met by developed than by developing countries, Chen and Mattoo (2008) conclude that specifically developing countries will be negatively affected by trade diversion from an MRA where they are not a member. Additionally, the stringency of the rules of origin play a crucial role for the effects on outsiders. If the rules of origin are very strict, then gains from the MRA are restricted to MRA member

\footnotetext{
${ }^{14}$ Note that Clausing (2001) uses prices rather than quantities in the welfare analysis, which is problematic (see Feenstra 2004). Additionally, the results from Clausing (2001) may be driven by the rapid growth of imports that would have occurred if CUSPTA would not have been in place (see Romalis 2007).
} 
countries, whereas otherwise also outside countries potentially gain from harmonization of standards of other countries.

Baller (2007) uses a gravity model accounting for heterogeneous firms to investigate the effects of MRAs on developed and developing countries. She distinguishes between MRAs for which she finds positive effects on the extensive (entering new markets) and intensive (volume of trade) margin, and harmonization of standards or technical regulations. For the latter she finds ambiguous effects. Specifically, in line with Chen and Mattoo (2008), she finds that developing countries' trade is hurt by regional harmonization while it increases trade with developed countries.

Fink and Jansen (2009) focus on services trade and argue that the scope for MRAs is likely to be limited. The reason is that concerning services, MRAs are mainly relevant for mode 4 movements. ${ }^{15}$ However, mode 4 trade is hardly affected by trade liberalization, making large gains from MRAs unlikely. Further, MRAs for services only apply to a small number of professional services sectors, like accounting, architects and engineering. And most of the MRAs do not implement automatic recognition of qualifications (OECD 2003), limiting their effect further.

There is also a recent paper by Cadot, Disdier, Fotagné (2013) that highlights trade diversion effects for non-tariff measures. They show that North-South PTAs hurt trade between developing countries. If the harmonization is based on regional standards, also exports of developing countries to developed countries are predicted to be negatively affected.

Let us summarize these empirical findings in the words of the World Trade Organization: "To sum up, evidence suggests that regional integration of TBT/SPS [Technical Barriers to Trade (TBT), Sanitary and Phytosanitary (SPS)] measures has trade-diverting effects, especially to the detriment of developing countries." (World Trade Report, 2012, page 152).

\subsection{The role of spill-overs for the welfare effects of a TTIP}

In their studies on the EU-Japan and the TTIP agreements, Francois, Sunesen, and Thelle (2009) and Francois, Manchin, Norberg, Pindyuk and Tomberger (2013) implement the idea of spill-overs as follows. Direct spill-overs lead to a reduction of NTMs amounting to $20 \%$ of the reduction achieved within the TTIP. For example, if trade costs fall by $10 \%$ between the US and the EU, trade costs for exporters to the EU or the US from third countries fall by $2 \%$. Indirect spill-overs are assumed to amount to $50 \%$ of the direct spill-over rate. With the above example, this implies that trade costs of EU or US exporters to third countries and trade costs applicable in trade flows within the group of third countries would go down by $1 \%$.

To see how our benchmark results reported in column [1] of Table 5 change, we implement the parameterization of spill-overs introduced by FMNPT. Table 7 reports

\footnotetext{
${ }^{15}$ Mode 4 movements are services supplied by nationals of one country in the territory of another. This includes independent services suppliers and employees of the services supplier of another country, like, for examples a doctor going from his home country to the patients' country to provide treatment there.
} 
summary statistics for four different specifications. Row [1] reproduces our preferred model, where both direct and indirect spill-overs are set to zero. Row [2] implements the default parameterization of FMNPT. The consequence is that, compared to [1], the unweighted mean over country-level welfare effects rises from about $-0.04 \%$ to $2.9 \%$. The most negative realization increases from $-3.1 \%$ to $-0.5 \%$, cutting it by almost a factor of six. Also, the GDP-weighted mean of welfare effects more than doubles from $1.6 \%$ to $3.9 \%$.

Table 7. The role of spill-overs: Summary statistics of welfare effects

\begin{tabular}{|c|c|c|c|c|c|c|c|c|}
\hline \multicolumn{3}{|c|}{ Specification } & \multicolumn{6}{|c|}{ Welfare Effects } \\
\hline & \multicolumn{2}{|c|}{ Spill-overs } & \multicolumn{2}{|c|}{ unweighted } & \multicolumn{2}{|c|}{ GDP-weighted } & \multirow[b]{2}{*}{ Min } & \multirow[b]{2}{*}{ Max } \\
\hline & direct & indirect & Mean & Std. Dev. & Mean & Std. Dev. & & \\
\hline [1] & 0.00 & 0.00 & -0.04 & 1.93 & 1.58 & 2.78 & -3.09 & 5.56 \\
\hline [2] & 0.20 & 0.50 & 2.89 & 3.01 & 3.90 & 3.39 & -0.53 & 13.29 \\
\hline [3] & 0.10 & 0.50 & 1.47 & 2.43 & 2.73 & 3.06 & -1.82 & 8.24 \\
\hline [4] & 0.20 & 0.00 & 0.88 & 3.27 & 3.07 & 4.12 & -2.19 & 9.59 \\
\hline [5] & 0.10 & 0.00 & 0.42 & 2.58 & 2.32 & 3.42 & -2.64 & 7.55 \\
\hline
\end{tabular}

Source: Authors' calculations.

Note. All specifications use the benchmark PTA effect, assume selection, and set $\varepsilon=7.173$ countries. Trade cost equations as in Table 3.

Rows [3] to [5] provide further analysis on alternative parameterizations of spill-overs, where either direct spill-overs are assumed to be only $10 \%$ of the trade cost reduction within a TTIP, or where indirect spill-overs are shut down completely. The latter turn out to be important: in their absence, the unweighted average welfare effect is $0.9 \%$ compared to $2.9 \%$ when they are assumed active. Also the lowest welfare effect in the sample moves close to the one obtained in the total absence of any spill-overs. Hence, if one means to reduce third country losses, one requires those indirect spill-overs to operate.

Rows [3] to [5] provide further analysis on alternative parameterizations of spill-overs, where either direct spill-overs are assumed to be only $10 \%$ of the trade cost reduction within a TTIP, or where indirect spill-overs are shut down completely. The latter turn out to be important: in their absence, the unweighted average welfare effect is $0.9 \%$ compared to $2.9 \%$ when they are assumed active. Also the lowest welfare effect in the sample moves close to the one obtained in the total absence of any spill-overs. Hence, if one means to reduce third country losses, one requires those indirect spill-overs to operate.

Figure 10 provides Kernel density plots of welfare effects for our sample of 173 countries under scenarios [1], [2] and [4]. The Figure shows how strongly spill-overs shift the distribution of welfare effects to the right.

We conclude that spill-overs from bilateral trade cost reductions to third countries can be powerful sources of additional welfare gains. However, the empirical and theoretical 
basis for modeling these effects is too thin to justify incorporating them into our benchmark model.

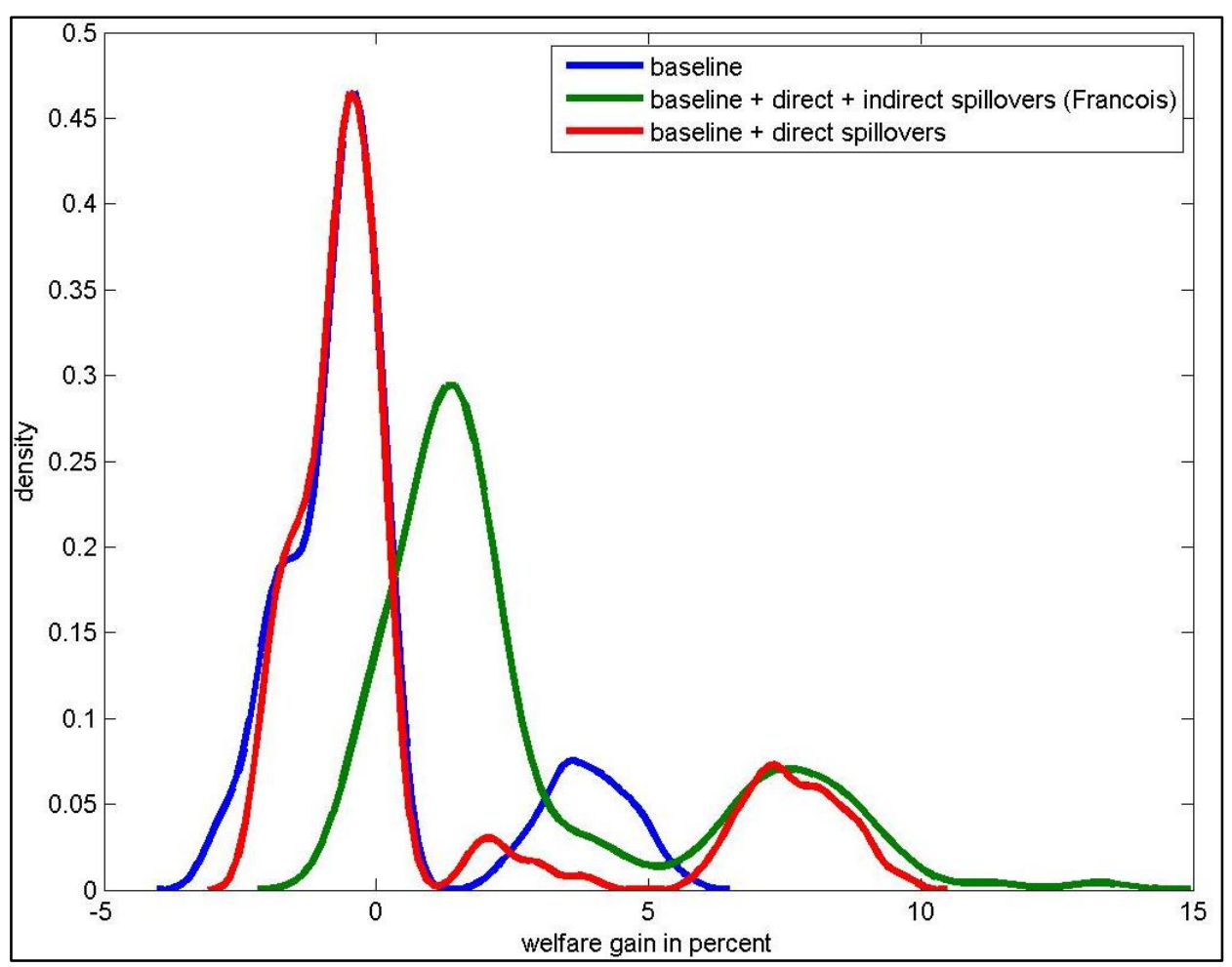

Figure 10. The effects of spill-overs on the distribution of welfare gains Source: Authors' calculations.

Notes: Kernel density estimates (Gaussian, with optimal bandwidth). Curves refer to rows [1] (baseline), [2] (direct and indirect spill-overs), and [4] (direct spill-overs) from Table 7.

\subsection{Conditioning effects of other regional mega deals}

We now turn towards the macroeconomic effects of other large trade agreements that are presently under negotiation, but which exclude the European Union: the Transpacific Partnership and the Regional Comprehensive Economic Partnership agreement.

The Transpacific Partnership (TPP) is a strategic economic partnership agreement between Brunei, Chile, New Zealand, and Singapore. It entered into force on January 1, 2006, under the name of the Trans-Pacific Strategic Economic Partnership Agreement (TPSEP). Currently, the US, Australia, Peru, Vietnam, Malaysia, Mexico, Canada, and Japan are negotiating to join the agreement. Several of the negotiating parties already maintain preferential trade agreements with each other; e.g., the US has PTAs in place with Australia, Canada, Chile, Peru, Mexico, and Singapore; similarly, Japan has PTAs 
with Peru, Vietnam, Malaysia, Mexico, Chile, and Singapore. Hence, TPP involves a substantial degree of consolidation of existing agreements. Nonetheless, it is a significant effort since it would create a free trade zone between the world's single largest (US) and third largest (Japan) economies.

The Regional Comprehensive Economic Partnership (RCEP) is a trade agreement between the 10 member states of ASEAN (Brunei, Cambodia, Indonesia, Lao PDR, Malaysia, Myanmar, the Philippines, Singapore, Thailand, and Vietnam) and the six countries with which ASEAN has existing Free Trade Agreements (PTAs) - Australia, China, India, Japan, Korea, and New Zealand. In relation to RCEP these six nonASEAN countries are known as the ASEAN Free Trade Partners (AFPs). As with TPP, the RCEP agreement involves consolidation of PTAs already in place.

Our quantitative strategy has the advantage that it can be used to assess the potential macroeconomic effects of any agreement, as long as one is willing to assume that its trade cost reducing effects can be inferred from the experience with existing preferential trade agreements.

Table 8. Other regional mega deals and cumulative effects: summary of welfare effects $(\%)$

\begin{tabular}{|c|c|c|c|c|c|c|c|}
\hline \multirow{2}{*}{\multicolumn{2}{|c|}{ Specifications }} & \multicolumn{2}{|c|}{ unweighted } & \multicolumn{2}{|c|}{ GDP-weighted } & \multirow[b]{2}{*}{ Min } & \multirow[b]{2}{*}{ Max } \\
\hline & & Mean & Std. Dev. & Mean & Std. Dev. & & \\
\hline \multicolumn{8}{|c|}{$\begin{array}{l}\text { Models with } \\
\text { selection }\end{array}$} \\
\hline [1] & TTIP & -0.04 & 1.93 & 1.58 & 2.78 & -3.09 & 5.56 \\
\hline [2] & TPP & -0.24 & 1.41 & 1.03 & 2.58 & -1.79 & 12.66 \\
\hline [3] & RCEP & -0.42 & 1.33 & 1.20 & 3.15 & -2.87 & 8.88 \\
\hline [4] & TPP gi & & & & & & \\
\hline \multirow{3}{*}{ [5] } & TTIP & -0.26 & 1.31 & 0.93 & 2.36 & -1.93 & 11.69 \\
\hline & RCEP & & & & & & \\
\hline & TTIP & -0.47 & 1.40 & 1.25 & 3.25 & -3.20 & 9.12 \\
\hline \multirow{2}{*}{ [6] } & TTIP g & & & & & & \\
\hline & RCEP & -0.05 & 1.82 & 1.49 & 2.71 & -2.76 & 5.25 \\
\hline \multirow{2}{*}{ [7] } & TTIP g & & & & & & \\
\hline & TPP & -0.08 & 1.99 & 1.63 & 2.81 & -3.20 & 5.71 \\
\hline
\end{tabular}

Source: Authors' calculations.

Note: All specifications use the benchmark PTA effect, assume selection, and set $\varepsilon=7.173$ countries. Trade cost equations as in Table 3.

Table 8 provides the summary of welfare effects for the TPP and the RCEP agreements. Row [1] reproduces our preferred specification for a TTIP. The rows entitled [2] and [3] report summary statistics for the other two main agreements under negotiation. Compared to a TTIP, the unweighted mean of welfare effects is much more negative for the TPP and the RCEP, amounting to $-0.2 \%$ and $-0.4 \%$, respectively. 
Nonetheless, the GDP-weighted averages are positive for both initiatives: $1.0 \%$ and $1.2 \%$, respectively. Compared to a TTIP, the other regional mega deals on their own yield smaller world-wide welfare gains, and those gains are more strongly concentrated as they include fewer countries. In the contexts of RCEP and TPP, the strongest gains accrue to Japan and New Zealand, respectively, and the largest losses to Micronesia (for both agreements).

In Rows [4] and [5], we summarize the welfare effects from enacting TPP and RCEP, respectively, given that a TTIP has already taken effect. The unweighted averages become slightly smaller, implying that losses to third countries (in particular to the US and EU member states) go up when a TTIP exists. In terms of GDP-weighted averages, we find that the TPP, introduced given that a TTIP already exists has a somewhat smaller welfare effect than when it comes to a world without the TTIP; the opposite is true for the RCEP.

Finally, Rows [6] and [7] reverse the order. They assume that the baseline equilibrium already incorporates the effects of the TPP or the RCEP. Interestingly, the emerging summary statistics resulting from the introduction of TTIP are not too different from those obtained from a baseline that does not feature the TPP or the RCEP. Note that we do not imply any dynamic effects from the specific order in which agreements are signed. The above counterfactual exercise only differ in the respectively chosen baseline scenario.

Table 9 provides details for the EU and some other countries. In EU member states, the TPP leads to a reduction of the EU-wide real per capita income of about $0.2 \%$ to $0.2 \%$, while the RCEP lowers real per capita income by $0.21 \%$ to $0.42 \%$, depending on whether these deals are introduced to a world without the TTIP or to a world with the TTIP. The fact that the average EU welfare effect from introducing the TPP with a TTIP already in place is so much more negative than the one from introducing TPP alone shows that some of the welfare gains accruing to EU member states from TTIP are eroded away when the US opens to the TPP members.

The TPP is particularly problematic for those EU member states that have strong trade ties with the US or Japan, two countries that would be included in the TPP. This is the case for the United Kingdom, for example. In contrast, the RCEP is most painful for countries trading a lot with Asia, in particular with China.

Figure 11 plots the welfare effects of introducing the RCEP against those of introducing the TPP (without having a TTIP) for the EU member states. The figure also shows a 45 degrees line. It becomes clear that most countries lie below that line. So, they lose more from the RCEP than from the TPP. Interestingly, however, the losses from the two initiatives are strongly and positively correlated. Broadly the same countries are vulnerable to the RCEP than to the TPP. The most affected countries would be Finland, Spain and the United Kingdom in case of TPP; and Finland, Cyprus, and the Baltic States in the case of RCEP. 
Table 9. Welfare effects: conditioning effects of different regional mega deals

\begin{tabular}{|c|c|c|c|c|c|c|c|c|}
\hline & & TTIP & TPP & RCEP & $\begin{array}{c}\text { [4] } \\
\text { TPP } \\
\text { after } \\
\text { TTIP }\end{array}$ & $\begin{array}{c}{[5]} \\
\text { RCEP } \\
\text { after } \\
\text { TTIP }\end{array}$ & $\begin{array}{c}6] \\
\text { TTIP } \\
\text { after } \\
\text { TPP } \\
\end{array}$ & $\begin{array}{c}\text { [7] } \\
\text { TTIP } \\
\text { after } \\
\text { RCEP }\end{array}$ \\
\hline 1 & Austria & 2.83 & -0.15 & -0.18 & -0.32 & -0.13 & 2.64 & 2.89 \\
\hline 2 & Belgium & 2.25 & -0.11 & -0.13 & -0.26 & -0.10 & 2.09 & 2.30 \\
\hline 3 & Bulgaria & 3.94 & -0.22 & -0.28 & -0.43 & -0.20 & 3.71 & 4.05 \\
\hline 4 & Croatia & 3.53 & -0.22 & -0.23 & -0.41 & -0.16 & 3.30 & 3.61 \\
\hline 5 & Cyprus & 4.36 & -0.25 & -0.35 & -0.46 & -0.24 & 4.11 & 4.50 \\
\hline 6 & Czech Rep. & 3.04 & -0.17 & -0.20 & -0.35 & -0.15 & 2.84 & 3.11 \\
\hline 7 & Denmark & 3.45 & -0.19 & -0.22 & -0.39 & -0.16 & 3.23 & 3.54 \\
\hline 8 & Estonia & 4.31 & -0.25 & -0.31 & -0.47 & -0.22 & 4.05 & 4.43 \\
\hline 9 & Finland & 4.60 & -0.28 & -0.34 & -0.50 & -0.23 & 4.33 & 4.74 \\
\hline 10 & France & 3.46 & -0.18 & -0.20 & -0.38 & -0.13 & 3.24 & 3.55 \\
\hline 11 & Germany & 3.48 & -0.19 & -0.22 & -0.38 & -0.15 & 3.26 & 3.57 \\
\hline 12 & Greece & 4.21 & -0.24 & -0.31 & -0.46 & -0.21 & 3.96 & 4.33 \\
\hline 13 & Hungary & 3.50 & -0.20 & -0.24 & -0.39 & -0.18 & 3.27 & 3.58 \\
\hline 14 & Ireland & 4.70 & -0.24 & -0.20 & -0.49 & -0.11 & 4.41 & 4.81 \\
\hline 15 & Italy & 3.86 & -0.21 & -0.25 & -0.42 & -0.17 & 3.62 & 3.97 \\
\hline 16 & Latvia & 4.10 & -0.24 & -0.29 & -0.45 & -0.21 & 3.85 & 4.22 \\
\hline 17 & Lithuania & 3.97 & -0.23 & -0.28 & -0.44 & -0.20 & 3.73 & 4.07 \\
\hline 18 & Luxembourg & 2.57 & -0.13 & -0.15 & -0.29 & -0.11 & 2.39 & 2.62 \\
\hline 19 & Malta & 4.84 & -0.26 & -0.27 & -0.50 & -0.16 & 4.56 & 4.97 \\
\hline 20 & Netherlands & 2.85 & -0.15 & -0.17 & -0.33 & -0.13 & 2.65 & 2.91 \\
\hline 21 & Poland & 3.51 & -0.20 & -0.24 & -0.39 & -0.17 & 3.29 & 3.60 \\
\hline 22 & Portugal & 4.80 & -0.26 & -0.26 & -0.50 & -0.16 & 4.52 & 4.93 \\
\hline 23 & Romania & 3.87 & -0.20 & -0.26 & -0.41 & -0.18 & 3.63 & 3.97 \\
\hline 24 & Slovak Rep. & 3.40 & -0.19 & -0.24 & -0.38 & -0.17 & 3.18 & 3.48 \\
\hline 25 & Slovenia & 3.14 & -0.17 & -0.20 & -0.35 & -0.15 & 2.93 & 3.21 \\
\hline 26 & Spain & 5.56 & -0.28 & -0.23 & -0.55 & -0.12 & 5.25 & 5.71 \\
\hline 27 & Sweden & 4.25 & -0.25 & -0.29 & -0.46 & -0.20 & 3.99 & 4.36 \\
\hline \multirow[t]{2}{*}{28} & UK & 5.14 & -0.27 & -0.24 & -0.53 & -0.13 & 4.84 & 5.27 \\
\hline & EU 28 & 3.94 & -0.21 & -0.22 & -0.42 & -0.15 & 3.70 & 4.05 \\
\hline 29 & United States & 4.89 & 2.14 & -0.66 & 2.06 & -0.61 & 4.82 & 4.95 \\
\hline 30 & Australia & -2.01 & 2.37 & 7.42 & 2.98 & 8.01 & -1.50 & -1.55 \\
\hline 31 & Brazil & -0.77 & -0.52 & -0.43 & -0.45 & -0.49 & -0.71 & -0.83 \\
\hline 32 & Canada & -3.09 & 0.27 & 0.16 & 0.70 & 0.05 & -2.73 & -3.20 \\
\hline 33 & China & -0.50 & -0.86 & 4.86 & -0.78 & 4.98 & -0.43 & -0.41 \\
\hline 34 & India & -0.31 & -0.24 & 1.75 & -0.20 & 1.77 & -0.27 & -0.30 \\
\hline 35 & Japan & -0.51 & 8.20 & 8.88 & 7.34 & 9.12 & -1.22 & -0.31 \\
\hline 36 & Mexico & -2.56 & -1.13 & -0.17 & -0.97 & -0.30 & -2.41 & -2.69 \\
\hline 37 & Norway & -1.91 & -0.27 & -0.29 & -0.17 & -0.38 & -1.81 & -2.01 \\
\hline 38 & Russian Fed. & -1.01 & -0.64 & -0.92 & -0.56 & -1.03 & -0.94 & -1.13 \\
\hline 39 & South Africa & -1.69 & -0.52 & -0.52 & -0.43 & -0.64 & -1.61 & -1.82 \\
\hline 40 & Turkey & -1.56 & -0.24 & -0.32 & -0.16 & -0.41 & -1.47 & -1.65 \\
\hline
\end{tabular}

Source: Authors' calculations. See the Appendix, Table A1 for further details. 


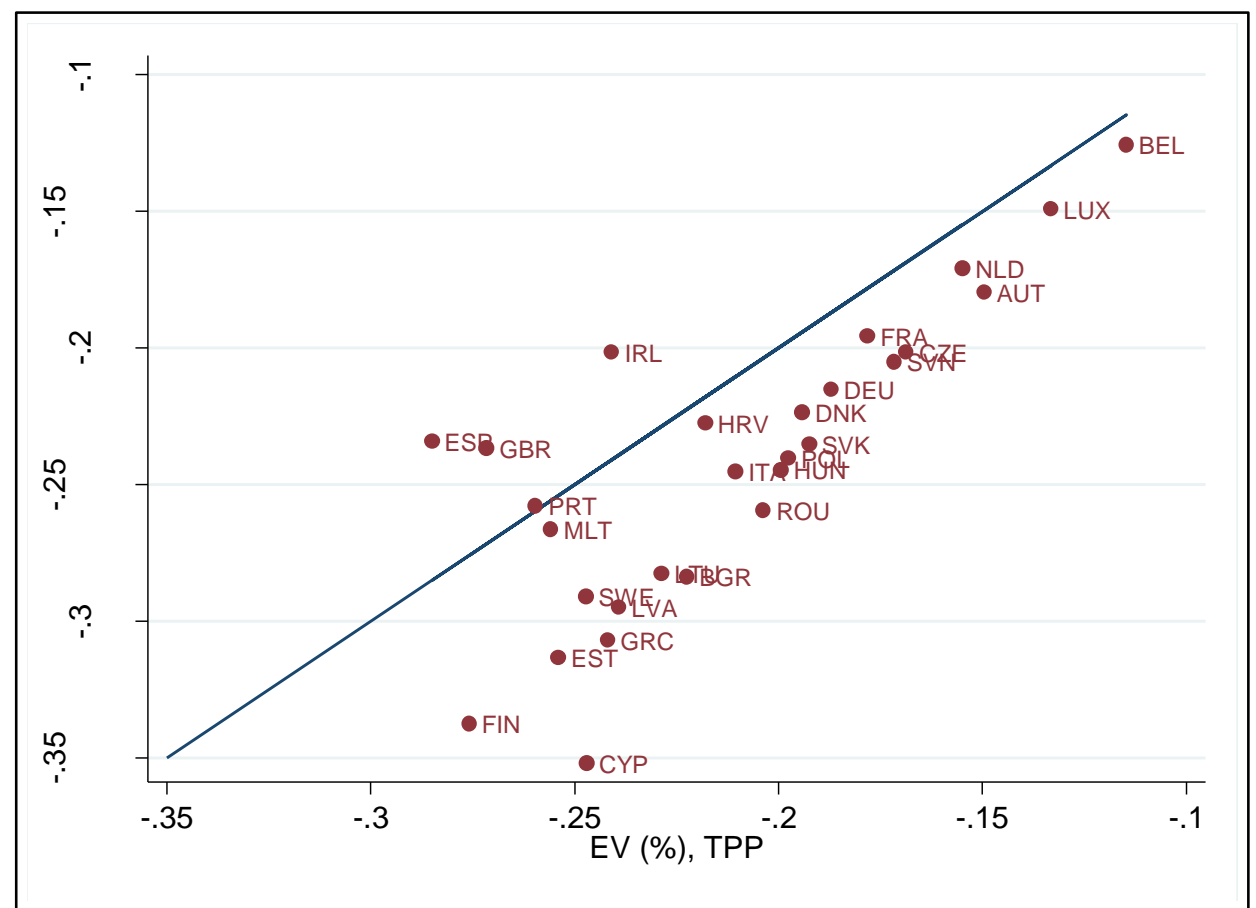

Figure 11. Welfare Effects of TPP and RCEP in the EU28

Source: Authors' calculations

\section{FURTHER ROBUSTNESS CHECKS: REGIONAL AGGREGATION AND TRADE ELASTICITIES}

\subsection{The role of the level of aggregation}

Anderson (2011) discusses how regional aggregation affects the welfare effects of trade policy changes. Lumping countries together into larger regions has non-trivial effects. Aggregation implies that part of international trade becomes internal trade with typically lower trade costs. In addition, the assumed underlying geography determined by the specified trade cost functions and the number of countries/regions changes. This, as can be seen by equations (2) and (3), directly affects trade flows, the multilateral resistances, and ultimately welfare. Most importantly, within the newly aggregated regions, all trade diversion effects are assumed away. This effectively limits the negative trade diversion effects within the aggregated regions and increases the net welfare effects of any international trade costs reduction for these regions.

Here, we aggregate the $28 \mathrm{EU}$ member states into a single entity and report the resulting welfare effects for a selection of regions. The aim is to make our exercise more directly comparable to FMNPT. Specifically, we follow Head and Mayer (2000, 2002), Helliwell and Verdier (2001), and Anderson and van Wincoop (2003, footnote 17) by 
calculating aggregate distances weighted by respective GDP shares of a country within the EU. We apply the same method to all other explanatory variables in our trade costs specification. Compared to the case where the EU is assumed to consist of 28 separate countries, welfare effects from a TTIP are numerically larger; see columns [A] and [B] of Table 10 .

Table 10. Welfare effects of a TTIP and regional aggregation

[A]

EU disaggregated EU as single entity

\begin{tabular}{lcc}
\hline European Union & 3.94 & 6.03 \\
United States & 4.89 & 6.62 \\
Australia & -2.01 & -2.72 \\
Brazil & -0.77 & -1.16 \\
Canada & -3.09 & -4.13 \\
China & -0.50 & -0.79 \\
India & -0.31 & -0.51 \\
Japan & -0.51 & -0.81 \\
Mexico & -2.56 & -3.50 \\
Norway & -1.91 & -3.24 \\
Russian Federation & -1.01 & -1.70 \\
South Africa & -1.69 & -2.83 \\
Turkey & -1.56 & -2.81 \\
\hline \hline
\end{tabular}

Source: Authors' calculations.

The aggregation eliminates all trade diversion effects within the EU, which increases the value of the agreement for the TTIP members. The flipside of the coin is that the non-member countries suffer larger negative welfare effects in this case. Indeed, the difference between the average welfare effects in the EU and in the US narrows when the EU is treated as a single entity. While the percentage increase in real per capita income is about 1.25 times larger in the US than in the EU when the 28 member states are treated separately, it is only 1.10 times larger when the EU is treated as a single entity. ${ }^{16}$

\subsection{Different trade elasticities}

We provide two further robustness checks. First, we investigate the choice of the trade elasticity. Second, we introduce search frictions into the labor market and investigate the aggregate welfare effects of introducing a TTIP.

\footnotetext{
${ }^{16}$ We also investigated the effect of TTIP when aggregating all countries in 11 regions, following Francois, Manchin, Norberg, Pindyuk and Tomberger (2013). The regions are ASEAN, China, EU, Eastern Europe, India, low income countries, MERCOSUR, Mediterranean countries, USA, other OECD countries, and rest of the world. We find broadly similar results. However, the EU gains significantly more in this scenario, and even more than the US, whose gains are predicted to be similar than in the scenarios reported in Table 10.
} 
Anderson and van Wincoop (2004) advocate a trade elasticity $\varepsilon$ in the neighborhood of 7 for studies using aggregate trade flows as ours. However, the literature has also used lower elasticities, see Bernard, Redding and Schott (2007) for an example. Lower values of trade elasticities tend to lead to higher gains from trade, since domestic and imported varieties are less easily substitutable.

Row [1] in Table 11 repeats our preferred specification for reference. Rows [2] and [3] use a trade elasticity of 5 instead of 7 in a model with and without selection. One can see quite clearly that a lower $\varepsilon$ does not affect the unweighted average effects of introducing TTIP by much, but it does blow up the standard deviation quite considerably. GDPweighted averages increase from $1.6 \%$ to $2.7 \%$ (selection); and the range of possible welfare realizations increases.

Table 11. Robustness checks: Different trade elasticities

\begin{tabular}{lccccccc}
\hline \hline \multirow{2}{*}{ Specification } & \multicolumn{6}{c}{ Results: cross-country moments } \\
& Parameters & \multicolumn{2}{c}{ unweighted } & \multicolumn{2}{c}{ GDP-weighted } \\
& $\boldsymbol{\varepsilon}$ & Mean & Std. & Mean & Std. & Min & Max \\
& & & Dev. & & Dev. & & \\
\hline$[1]$ & 7.00 & -0.04 & 1.93 & 1.58 & 2.78 & -3.09 & 5.56 \\
{$[2]$} & 5.00 & 0.02 & 3.31 & 3.90 & 3.39 & -4.80 & 9.78 \\
{$[3]$ (no sel.) } & 5.00 & -0.27 & 3.36 & 2.73 & 3.06 & -4.81 & 9.73 \\
\hline \hline
\end{tabular}

Note: All specifications use the benchmark PTA effect. Specification [1] and [2] allow for endogenous selection of countries into trade. 173 countries. Trade costs as in Table 3.

\section{POLICY CONCLUSIONS}

The heated public debate on the proposed TTIP goes much beyond standard economic analysis of the pros and cons of regional trade integration. It addresses the fundamental tension between the desirability of democratic politics, open international markets, and the scope of the nation state (Rodrik, 2011). In our paper, we have narrowed our focus on the potential economic impact of a TTIP on EU member states and the world. Nonetheless, our research does offer some important insights for economic policy.

First, our analysis suggests substantial economic benefits for the average EU citizen (about EUR 1000 per year). This is larger than what other studies using different methods and assumptions find and what many critical observers suppose. While we do not deny risks from a transatlantic agreement (see below), economic benefits are big enough to tilt the balance in favor of a TTIP. So, in our view, it is worth investing political capital into the project. Moreover, in contrast to wide-spread public opinion, a TTIP would not benefit core EU countries more than the periphery. While the robustness of this finding is still to be ascertained, it would imply that there is no need to step up regional support programs following the conclusion of a TTIP. Finally, our result that 
the US gains more than the EU has captured public attention. Clearly, this possibility should have no bearing on the desirability of a TTIP for the EU.

Second, negotiators have set their ambitions high. Their goal is to conclude a "comprehensive, ambitious agreement that addresses a broad range of bilateral trade and investment issues, including regulatory issues" [and that] "goes beyond what the United States and the EU have achieved in previous trade agreements." ${ }^{17}$ In our analysis, we have remained more modest: we have assumed that a TTIP would reduce trade costs by as much as existing agreements have. However, we know that existing agreements often have holes (exceptions for agriculture, services), and that they often do not cover contentious issues pertaining to regulatory convergence or to investment (such as the much disputed investor-state dispute settlement mechanisms); see Dür, Baccini and Elsig (2014). It follows that the welfare gains from a TTIP could be substantial even if some of the most problematic elements are dropped.

Third, if TTIP operates like the average existing trade agreement, it will most likely have discriminatory effects on third countries. Unlike other authors (e.g., FMNPT), we have not assumed that bilateral negotiations will also lead to lower trade costs of nonparticipating countries amongst themselves and with TTIP members. While it is conceivable that the establishment of global standards benefits all trading nations, we have refrained from assuming spill-overs: (i) there is no serious evidence yet that would support this modeling choice; (ii) the TTIP is, amongst other things, a very classical market access liberalization exercise, e.g., in the services, public procurement, agri-food, or investment liberalization areas; (iii) in the area of regulatory convergence, TTIP will like the EU single market program - most likely result in mutual recognition of standards across the Atlantic rather than in the establishment of a global standard. And even if it did, whether EU or US regulators automatically admit goods or services from third countries that satisfy EU or US standards is by no means guaranteed. This will depend on the small print and on the implementation of the agreement. Hence, a TTIP must be expected to have Vinerian consequences. Policymakers should work on measures to mitigate negative third country effects, e.g., by applying generous rules of origin, or by pursuing further multilateral trade liberalization at the WTO level.

Fourth, in our analysis, we have compared long-run equilibria. We have not discussed adjustment dynamics. Also, we have abstracted from distributional consequences. More research on these issues would be highly welcome. However, in the particular case of a TTIP, there are reasons to be optimistic. We have motivated our modeling strategy, inter alia, by the fact that transatlantic trade is strongly intra-industry. This implies that adjustment processes will predominantly involve intra-industry reallocation. This should keep adjustment costs low as workers change jobs within sectors, and it should also lead to speedy adjustment. Thus, frictional unemployment on the adjustment path, should remain limited. Moreover, the structure of factor endowments across the Atlantic is not too different. This leaves little scope for Stolper-Samuelson type effects. So, there are

\footnotetext{
17 Final Report of the High Level Working Group on Jobs and Growth, February 11, 2013, available at trade.ec.europa.eu/doclib/html/150519.htm.
} 
reasons to believe that distributional consequences from a TTIP should be limited, too. Nonetheless, policymakers are advised not to obstruct the working of the labor market and to ensure that a TTIP does not result in more monopolistic market structures that result in new barriers to entry. 


\section{REFERENCES}

Anderson, J.E. (2011), “The Gravity Model”, Annual Review of Economics, 3: 133-160.

Anderson, J.E., Mario Larch and Yoto V. Yotov (2014a), "Growth and Trade: A Structural Estimation Framework", unpublished manuscript.

Anderson, J.E., Mario Larch and Yoto V. Yotov (2014b), "On the Effects of the Transatlantic Trade and Investment Partnership on Trade and Growth”, unpublished manuscript.

Anderson, J. E. and van Wincoop, E. (2003), "Gravity with Gravitas: A Solution to the Border Puzzle", American Economic Review, 93(1): 170-192.

Anderson, James E. and Eric van Wincoop. (2004), "Trade Costs", Journal of Economic Literature, 42(3): 691-751.

Anderson , James and Yoto Yotov (2010), "Specialization: Pro- and Anti-globalizing, 1990-2002", NBER Working Papers No. 16301.

Anderson, James and Yoto Yotov (2011), "Terms of Trade and Global Efficiency Effects of Free Trade Agreements, 1990-2002”, NBER Working Paper No. 17003.

Arkolakis, C., Costinot, A., and Rodríguez-Clare, A. (2012), "New Trade Models, Same Old Gains?", American Economic Review, 102(1): 94-130.

Baier, Scott L., and Jeffrey H. Bergstrand (2002), "On the Endogeneity of International Trade Flows and Free Trade Agreements", Unpublished.

Baier, Scott L., and Jeffrey H. Bergstrand (2004), "Economic Determinants of Free Trade Agreements." Journal of International Economics, 64(1): 29-63.

Baier, Scott L., and Jeffrey H. Bergstrand (2007), "Do Free Trade Agreements Actually Increase Members' International Trade?”, Journal of International Economics, 71(1): 72-95.

Baier, Scott L., and Jeffrey H. Bergstrand (2009), "Estimating the Effects of Free Trade Agreements on International Trade Flows Using Matching Econometrics", Journal of International Economics, 77(1): 63-76.

Baldwin, Richard (2011), " $21^{\text {st }}$ Century Regionalism: Filling the gap between $21^{\text {st }}$ century trade and $20^{\text {th }}$ century trade rules", Staff Working Paper ERSD-2011-08, World Trade Organization.

Baller, Silja (2007), "Trade Effects of Regional Standards. A Heterogeneous Firms Approach", Washington, D.C.: World Bank Policy Research Working Paper 4124.

Berden, Koen, Joseph Francois, Martin Thelle, Paul Wymenga, and Saara Tamminen (2009), "Non-Tariff Measures in EU-US Trade and Investment- An Economic Analysis", Report OJ 2007/S 180-219493 for the European Commission: Directorate-General for Trade.

Bergstrand, Jeff, Peter H. Egger, and Mario Larch (2013), "Gravity Redux: Estimation of gravityEquation Coefficients, Elasticities of substitution, and General Equilibrium Comparative Statics under Asymmetric Bilateral Trade Costs", Journal of International Economics, 89(1): 110-121.

Bernard, Andrew B., Stephen J. Redding and Peter K. Schott (2007), "Comparative Advantage and Heterogeneous Firms", Review of Economic Studies 74(1): 31-76.

Cadot, Olivier, Disdier, Anne-Célia and Lionel Fontagné (2013), "North-South Standards Harmonization and International Trade", World Bank Economic Review, forthcoming.

Chang, Won and L. Alan Winters (2002), "How Regional Blocs Affect Excluded Countries: The Price Effects of MERCOSUR", American Economic Review, 92(4): 889-904.

Chen, Maggie Xiaoyang and Aaditya Mattoo (2008), "Regionalism in standards: good or bad for trade?", Canadian Journal of Economics, 41(3): 838-863.

Chen, Natalie and Dennis Novy (2012), "On the Measurement of Trade Costs: Direct vs. Indirect Approaches to Quantifying Standards and Technical Regulations", World Trade Review 11(3): 401-414.

Cipollina, Maria and Luca Salvatici (2010), "Reciprocal Trade Agreements in Gravity Models: A Meta Analysis", Review of International Economics, 18(1): 63-80.

Clausing, Kimberley A. (2001), "Trade Creation and Trade Diversion in the Canada-U.S. Free Trade Agreement", Canadian Journal of Economics, 34(3): 677-696.

Costinot, Arnaud and Andrés Rodriguez-Clare (2014), "Trade Theory with Numbers: Quantifying the Consequences of Globalization", Chapter 4 in Gopinath, Helpman and Rogoff, Elsevier (eds.) The Handbook of International Economics, 197-261.

Dür, Andreas, Leonardo Baccini, and Manfred Elsig (2014), “The Design of International Trade Agreements: Introducing a New Dataset”, Review of International Organizations, 9(3): 353-375. 
Eaton, Jonathan and Samuel Kortum (2005), “Technology and the Global Economy: A Framework for Quantitative Analysis", manuscript in progress for Princeton University Press, Princeton, New Jersey.

Egger, Peter, Mario Larch, Kevin Staub, and Rainer Winkelmann (2011), "The Trade Effects of Endogenous Preferential Trade Agreements", American Economic Journal: Economic Policy, 3: 113-143.

Egger, Peter and Mario Larch (2011), “An Assessment of the Europe Agreements' Effects on Bilateral Trade, GDP, and Welfare”, European Economic Review, 55: 263-279.

Feenstra, Robert (2004), "Advanced International Trade: Theory and Evidence", Princeton University Press.

Felbermayr, Gabriel, Mario Larch, Lisandra Flach, Erdal Yalcin and Sebastian Benz (2013), "Dimensionen und Auswirkungen eines Freihandelsabkommens zwischen der EU und den USA", ifo Forschungsbericht 62.

Felbermayr, Gabriel and Mario Larch (2013), "The Transatlantic Trade and Investment Partnership (TTIP): Potentials, Problems and Perspectives ", CESifo Forum, 14 (2): 49-60, 2013.

Fink, Carsten and Mario Jansen (2009), "Services Provisions in Regional Trade Agreements: Stumbling Blocks or Building Blocks for Multilateral Liberalization?", in Baldwin, R. E. and Low, P. (eds.), Multilateralizing Regionalism: Challenges for the Global Trading System, Cambridge, Cambridge University Press.

Fontagné, L., J. Gourdon, and S. Jean (2013), Transatlantic Trade: Whither Partnership, Which Economic Consequences? CEPII Policy Brief 2013-01, Paris.

Francois, Joseph, Miriam Manchin, Hanna Norberg, Olga Pindyuk, and Patrick Tomberger (2013), "Reducing Transatlantic Barriers to Trade and Investment: An Economic Assessment", Report TRADE10/A2/A16 for the European Commission.

Francois, Joseph, Even Sunesen and Martin Thelle (2009), "Asessment of Barriers to Trade and Investment between the EU and Japan", Report TRADE/07/A2 for the European Commission.

Grossman, Gene and Elhanan Helpman (1991), "Innovation and Growth in the Global Economy", MIT Press, Cambridge, Massachusetts.

Hamilton, Daniel and Joseph Quinlan (2014), "The Transatlantic Economy 2014: Annual Survey of Jobs, Trade and Investment between the United States and Europe", Center for Transatlantic Relations, Washington D.C.

Head, Keith and Thierry Mayer (2000), "Non-Europe: The Magnitude and Causes of Market Fragmentation in Europe," Weltwirtschaftliches Archiv, 136(2): 284-314.

Head, Keith and Thierry Mayer (2002), "Illusory Border Effects: Distance Mismeasurement Inflates Estimates of Home Bias in Trade," CEPII Working Paper No $2002-01$.

Head, Keith and Thierry Mayer (2014), "Gravity Equations: Workhorse, Toolkit, and Cookbook", Chapter 3 in Gopinath, Helpman and Rogoff, Elsevier (eds.) The Handbook of International Economics Vol. 4, 131-195.

Heckman, James J., Lance Lochner and Christopher Taber (1998), "General-Equilibrium Treatment Effects: A Study of Tuition Policy”, American Economic Review, 88(2): 381-86.

Helliwel, John F. and Geneviève Verdier (2001), "Measuring Internal Trade Distances: A New Method Applied to Estimate Provincial Border Effects in Canada," Canadian Journal of Economics, 34(4): 1024-1041.

Kox, Henk and Arjan Lejour (2006), "Dynamic effects of European services liberalization: more to be gained", MPRA Paper No.3751.

Krugman, Paul R. (1980), "Scale Economies, Product Differentiation, and the Pattern of Trade". American Economic Review, 70(5): 950-959.

Magee, Christopher S. (2003), "Endogenous Preferential Trade Agreements: An Empirical Analysis", Contributions to Economic Analysis and Policy, 2(1).

OECD (2003), "Service Providers on the Move: Mutual Recognition Agreements", TD/TC/WP(2002)48/Final, available at hTPP://search.oecd.org/officialdocuments/displaydocum entpdf/?doclanguage $=$ en $\&$ cote $=$ td/tc/wp(2002) $48 /$ final.

Panagariya, Arvind (2000), "Preferential Trade Liberalization: The Traditional Theory and New Developments", Journal of Economic Literature, 38(2): 287-331.

Rodrik, Dani (2011), "The Globalization Paradox: Democracy and the Future of the World Economy“, W.W. Norton, New York and London.

Romalis, John (2007), "NAFTA's and CUSPTA's Impact on International Trade", Review of Economics and Statistics, 89(3): 416-35. 
Santos Silva, J.M.C. and Tenreyro, S. (2006), “The Log of Gravity”, Review of Economics and Statistics, 88(4): 641-658.

Santos Silva, J.M.C. and Tenreyro, S. (2010), "On the Existence of the Maximum Likelihood Estimates for Poisson Regression”, Economics Letters, 107(2): 310-312.

Santos Silva, J.M.C. and Tenreyro, S. (2011), "Further Simulation Evidence on the Performance of the Poisson-PML Estimator", Economics Letters, 112(2): 220-222.

Trefler, Daniel (2004), "The Long and Short of the Canada-U.S. Free Trade Agreement", American Economic Review, 94(4): 870-895.

Viner, Jacob (1950), "The Customs Union Issue", New York: Carnegie Endowment for International Peace.

World Trade Organization (2012), "World Trade Report 2012 - Trade and Public Policies: A Closer Look at Non-Tariff Measures in the 21st Century", available at hTPP://www.wto.org/ENGLISH/res_e/reser_e/wtr_e.htm. 


\section{APPENDIX}

Table A1. Welfare results across different scenarios

\begin{tabular}{|c|c|c|c|c|c|c|c|c|c|}
\hline \multirow[t]{2}{*}{ Country } & \multirow[t]{2}{*}{ code } & \multirow[t]{2}{*}{ TTIP } & \multicolumn{2}{|c|}{ PTA with } & \multirow[t]{2}{*}{$\begin{array}{c}\text { Open- } \\
\text { ness }\end{array}$} & \multicolumn{4}{|c|}{$\begin{array}{l}\text { Welfare effects in different } \\
\text { scenarios }\end{array}$} \\
\hline & & & $\mathrm{EU}$ & USA & & $\begin{array}{l}\text { TTIP } \\
\text { full }\end{array}$ & $\begin{array}{c}\text { TTIP } \\
\text { only } \\
\text { tariffs }\end{array}$ & RCEP & TPP \\
\hline Austria & AUT & 1 & n.a. & n.a. & 43.63 & 2.83 & 0.22 & -0.18 & -0.15 \\
\hline Belgium & BEL & 1 & n.a. & n.a. & 91.17 & 2.25 & 0.17 & -0.13 & -0.11 \\
\hline Bulgaria & BGR & 1 & n.a. & n.a. & 58.29 & 3.94 & 0.33 & -0.28 & -0.22 \\
\hline Croatia & HRV & 1 & n.a. & n.a. & 27.95 & 3.53 & 0.38 & -0.23 & -0.22 \\
\hline Cyprus & CYP & 1 & n.a. & n.a. & 19.88 & 4.36 & 0.37 & -0.35 & -0.25 \\
\hline Czech Republic & CZE & 1 & n.a. & n.a. & 75.63 & 3.04 & 0.24 & -0.20 & -0.17 \\
\hline Denmark & DNK & 1 & n.a. & n.a. & 31.59 & 3.45 & 0.28 & -0.22 & -0.19 \\
\hline Estonia & EST & 1 & n.a. & n.a. & 75.47 & 4.31 & 0.36 & -0.31 & -0.25 \\
\hline Finland & FIN & 1 & n.a. & n.a. & 30.06 & 4.60 & 0.39 & -0.34 & -0.28 \\
\hline France & FRA & 1 & n.a. & n.a. & 23.78 & 3.46 & 0.28 & -0.20 & -0.18 \\
\hline Germany & DEU & 1 & n.a. & n.a. & 37.55 & 3.48 & 0.28 & -0.22 & -0.19 \\
\hline Greece & GRC & 1 & n.a. & n.a. & 18.96 & 4.21 & 0.35 & -0.31 & -0.24 \\
\hline Hungary & HUN & 1 & n.a. & n.a. & 79.88 & 3.50 & 0.28 & -0.24 & -0.20 \\
\hline Ireland & IRL & 1 & n.a. & n.a. & 42.54 & 4.70 & 0.39 & -0.20 & -0.24 \\
\hline Italy & ITA & 1 & n.a. & n.a. & 24.47 & 3.86 & 0.32 & -0.25 & -0.21 \\
\hline Latvia & LVA & 1 & n.a. & n.a. & 54.60 & 4.10 & 0.34 & -0.29 & -0.24 \\
\hline Lithuania & LTU & 1 & n.a. & n.a. & 72.78 & 3.97 & 0.33 & -0.28 & -0.23 \\
\hline Luxembourg & LUX & 1 & n.a. & n.a. & 42.35 & 2.57 & 0.20 & -0.15 & -0.13 \\
\hline Malta & MLT & 1 & n.a. & n.a. & 57.97 & 4.84 & 0.41 & -0.27 & -0.26 \\
\hline Netherlands & NLD & 1 & n.a. & n.a. & 80.89 & 2.85 & 0.22 & -0.17 & -0.15 \\
\hline Poland & POL & 1 & n.a. & n.a. & 38.74 & 3.51 & 0.28 & -0.24 & -0.20 \\
\hline Portugal & PRT & 1 & n.a. & n.a. & 30.68 & 4.80 & 0.40 & -0.26 & -0.26 \\
\hline Romania & ROU & 1 & n.a. & n.a. & 37.75 & 3.87 & n.a. & -0.26 & -0.20 \\
\hline Slovak & SVK & 1 & n.a. & n.a. & 87.36 & 3.40 & 0.27 & -0.24 & -0.19 \\
\hline \multicolumn{10}{|l|}{ Republic } \\
\hline Slovenia & SVN & 1 & n.a. & n.a. & 70.67 & 3.14 & 0.25 & -0.20 & -0.17 \\
\hline Spain & ESP & 1 & n.a. & n.a. & 23.60 & 5.56 & 0.48 & -0.23 & -0.28 \\
\hline Sweden & SWE & 1 & n.a. & n.a. & 31.93 & 4.25 & 0.35 & -0.29 & -0.25 \\
\hline United & GBR & 1 & n.a. & n.a. & 23.20 & 5.14 & 0.44 & -0.24 & -0.27 \\
\hline \multicolumn{10}{|l|}{ Kingdom } \\
\hline United States & USA & 1 & n.a. & n.a. & 11.95 & 4.89 & 0.41 & -0.66 & 2.14 \\
\hline Afghanistan & AFG & 0 & 0 & 0 & 15.98 & -0.45 & n.a. & -0.66 & -0.21 \\
\hline Albania & ALB & 0 & 1 & 0 & 27.08 & -2.01 & -0.18 & -0.27 & -0.26 \\
\hline Algeria & DZA & 0 & 1 & 0 & 29.35 & -1.68 & -0.15 & -0.18 & -0.18 \\
\hline Angola & AGO & 0 & 0 & 0 & 42.49 & -0.31 & -0.04 & -0.30 & -0.21 \\
\hline
\end{tabular}




\begin{tabular}{|c|c|c|c|c|c|c|c|c|c|}
\hline Antigua and & ATG & 0 & 1 & 0 & 25.79 & -1.66 & -0.16 & -0.37 & -1.01 \\
\hline \multicolumn{10}{|l|}{ Barbuda } \\
\hline Argentina & ARG & 0 & 0 & 0 & 15.74 & -0.60 & -0.06 & -0.27 & -0.41 \\
\hline Armenia & ARM & 0 & 0 & 0 & 28.62 & -0.70 & n.a. & -0.53 & -0.45 \\
\hline Australia & AUS & 0 & 0 & 1 & 16.89 & -2.01 & -0.17 & 7.42 & 2.37 \\
\hline Azerbaijan & AZE & 0 & 0 & 0 & 31.75 & -0.55 & -0.05 & -0.48 & -0.40 \\
\hline Bahamas, The & BHS & 0 & 1 & 0 & 27.30 & -2.21 & -0.21 & 0.08 & -1.06 \\
\hline Bangladesh & BGD & 0 & 0 & 0 & 25.46 & 0.03 & n.a. & -1.78 & -0.13 \\
\hline Barbados & BRB & 0 & 1 & 0 & 27.69 & -1.50 & n.a. & -0.50 & -0.89 \\
\hline Belarus & BLR & 0 & 0 & 0 & 73.02 & -0.74 & -0.07 & -0.32 & -0.32 \\
\hline Benin & BEN & 0 & 0 & 0 & 23.82 & -0.19 & -0.04 & -0.09 & -0.07 \\
\hline Bermuda & $\mathrm{BMU}$ & 0 & 0 & 0 & 8.41 & -2.30 & -0.23 & -0.21 & -0.86 \\
\hline Bhutan & BTN & 0 & 0 & 0 & 45.24 & -0.41 & n.a. & -0.70 & -0.53 \\
\hline Bolivia & BOL & 0 & 0 & 0 & 35.14 & -0.64 & -0.07 & -0.26 & -0.43 \\
\hline Bosnia and & $\mathrm{BIH}$ & 0 & 1 & 0 & 43.47 & -2.16 & -0.19 & -0.26 & -0.25 \\
\hline \multicolumn{10}{|l|}{ Herzegovina } \\
\hline Botswana & BWA & 0 & 0 & 0 & 48.25 & -0.03 & 0.00 & -0.25 & -0.13 \\
\hline Brazil & BRA & 0 & 0 & 0 & 10.56 & -0.77 & -0.05 & -0.43 & -0.52 \\
\hline Brunei & BRN & 0 & 0 & 0 & 49.99 & 0.08 & 0.02 & -2.70 & 1.71 \\
\hline \multicolumn{10}{|l|}{ Darussalam } \\
\hline Burkina Faso & BFA & 0 & 0 & 0 & 25.64 & -0.60 & -0.06 & -0.27 & -0.20 \\
\hline Burundi & BDI & 0 & 0 & 0 & 18.40 & -0.25 & -0.04 & -0.71 & -0.18 \\
\hline Cabo Verde & $\mathrm{CPV}$ & 0 & 0 & 0 & 22.41 & -0.61 & -0.09 & -0.32 & -0.22 \\
\hline Cambodia & KHM & 0 & 0 & 0 & 68.38 & -0.22 & n.a. & 1.47 & -0.46 \\
\hline Cameroon & CMR & 0 & 1 & 0 & 22.91 & -1.30 & -0.19 & -0.26 & -0.28 \\
\hline Canada & CAN & 0 & 0 & 1 & 26.12 & -3.09 & -0.27 & 0.16 & 0.27 \\
\hline Central African & CAF & 0 & 0 & 0 & 12.13 & -0.54 & n.a. & -0.39 & -0.31 \\
\hline \multicolumn{10}{|l|}{ Republic } \\
\hline Chad & TCD & 0 & 0 & 0 & 25.22 & -0.60 & -0.14 & -0.39 & -0.31 \\
\hline Chile & CHL & 0 & 1 & 1 & 29.29 & -1.54 & -0.14 & -0.68 & -1.00 \\
\hline China & $\mathrm{CHN}$ & 0 & 0 & 0 & 23.50 & -0.50 & -0.04 & 4.86 & -0.86 \\
\hline Colombia & $\mathrm{COL}$ & 0 & 1 & 1 & 16.14 & -0.71 & -0.07 & -0.27 & -0.51 \\
\hline Comoros & $\mathrm{COM}$ & 0 & 0 & 0 & 27.27 & -0.44 & -0.08 & -0.53 & -0.44 \\
\hline Congo, Rep. & $\mathrm{COG}$ & 0 & 0 & 0 & 59.22 & -0.47 & n.a. & -0.31 & -0.24 \\
\hline Costa Rica & CRI & 0 & 1 & 1 & 32.10 & -2.64 & -0.23 & 0.05 & -1.34 \\
\hline Cote d'Ivoire & CIV & 0 & 1 & 0 & 44.87 & -1.78 & -0.15 & -0.36 & -0.39 \\
\hline Dominica & DMA & 0 & 1 & 0 & 24.50 & -1.92 & -0.18 & 0.07 & -0.94 \\
\hline Dominican & DOM & 0 & 1 & 1 & 22.52 & -2.86 & -0.25 & 0.06 & -1.40 \\
\hline \multicolumn{10}{|l|}{ Republic } \\
\hline Ecuador & ECU & 0 & 0 & 0 & 29.23 & -0.85 & -0.08 & -0.31 & -0.56 \\
\hline Egypt, Arab & EGY & 0 & 1 & 0 & 18.87 & -1.16 & -0.10 & -0.24 & -0.20 \\
\hline
\end{tabular}




\begin{tabular}{|c|c|c|c|c|c|c|c|c|c|}
\hline \multicolumn{10}{|l|}{ Rep. } \\
\hline El Salvador & SLV & 0 & 1 & 1 & 32.70 & -2.78 & -0.25 & 0.07 & -1.38 \\
\hline Equatorial & GNQ & 0 & 0 & 0 & 60.74 & -0.55 & n.a. & -0.46 & -0.34 \\
\hline \multicolumn{10}{|l|}{ Guinea } \\
\hline Eritrea & ERI & 0 & 0 & 0 & 22.96 & -0.39 & n.a. & -0.35 & -0.27 \\
\hline Ethiopia & ETH & 0 & 0 & 0 & 18.03 & -1.00 & -0.09 & -0.86 & -0.70 \\
\hline Fiji & FJI & 0 & 1 & 0 & 43.38 & -1.33 & -0.10 & -1.28 & -1.05 \\
\hline Gabon & GAB & 0 & 0 & 0 & 43.26 & -0.58 & -0.07 & -0.27 & -0.21 \\
\hline Gambia, The & GMB & 0 & 0 & 0 & 26.45 & -0.50 & -0.09 & -0.27 & -0.19 \\
\hline Georgia & GEO & 0 & 0 & 0 & 32.45 & -0.61 & -0.06 & -0.49 & -0.42 \\
\hline Ghana & GHA & 0 & 0 & 0 & 36.85 & -0.63 & -0.06 & -0.40 & -0.41 \\
\hline Grenada & GRD & 0 & 1 & 0 & 24.14 & -0.19 & -0.07 & -0.50 & -0.29 \\
\hline Guatemala & GTM & 0 & 1 & 1 & 26.99 & -2.81 & -0.24 & 0.07 & -1.40 \\
\hline Guinea & GIN & 0 & 0 & 0 & 32.85 & -0.28 & -0.04 & -0.07 & -0.05 \\
\hline Guinea-Bissau & GNB & 0 & 0 & 0 & 23.11 & -0.74 & -0.15 & -0.52 & -0.35 \\
\hline Guyana & GUY & 0 & 0 & 0 & 56.13 & -0.73 & -0.08 & -0.22 & -0.49 \\
\hline Haiti & HTI & 0 & 0 & 0 & 23.08 & -2.15 & -0.17 & 0.06 & -1.06 \\
\hline Honduras & HND & 0 & 1 & 1 & 51.81 & -1.62 & -0.14 & -0.45 & -0.98 \\
\hline Hong Kong & HKG & 0 & 0 & 0 & 198.97 & -0.18 & -0.02 & -2.64 & -0.15 \\
\hline \multicolumn{10}{|l|}{ SAR, China } \\
\hline Iceland & ISL & 0 & 1 & 0 & 36.19 & -1.80 & -0.16 & -0.36 & -0.39 \\
\hline India & IND & 0 & 0 & 0 & 21.05 & -0.31 & -0.03 & 1.75 & -0.24 \\
\hline Indonesia & IDN & 0 & 0 & 0 & 21.55 & -0.09 & -0.01 & -2.52 & -1.28 \\
\hline Iraq & IRQ & 0 & 0 & 0 & 35.07 & -0.12 & n.a. & -0.11 & -0.01 \\
\hline Israel & ISR & 0 & 1 & 1 & 26.92 & -1.91 & -0.16 & -0.10 & -0.60 \\
\hline Jamaica & JAM & 0 & 1 & 0 & 28.13 & -1.72 & -0.17 & -0.49 & -1.03 \\
\hline Japan & JPN & 0 & 0 & 0 & 14.13 & -0.51 & -0.04 & 8.88 & 8.20 \\
\hline Jordan & JOR & 0 & 1 & 1 & 46.07 & -1.88 & -0.17 & -0.07 & -0.62 \\
\hline Kazakhstan & KAZ & 0 & 0 & 0 & 33.61 & -0.48 & -0.05 & -0.73 & -0.43 \\
\hline Kenya & KEN & 0 & 0 & 0 & 27.54 & -0.67 & -0.09 & -0.31 & -0.26 \\
\hline Kiribati & KIR & 0 & 0 & 0 & 31.43 & 0.26 & n.a. & -2.24 & -1.45 \\
\hline Korea, Rep. & KOR & 0 & 1 & 1 & 47.25 & -0.54 & -0.05 & 2.99 & -0.39 \\
\hline Kyrgyz & KGZ & 0 & 0 & 0 & 56.12 & -0.25 & 0.00 & -0.62 & -0.44 \\
\hline \multicolumn{10}{|l|}{ Republic } \\
\hline Lao PDR & LAO & 0 & 0 & 0 & 27.08 & 0.08 & n.a. & 0.45 & -0.44 \\
\hline Lebanon & LBN & 0 & 1 & 0 & 32.09 & -1.53 & n.a. & -0.30 & -0.29 \\
\hline Lesotho & LSO & 0 & 0 & 0 & 75.59 & 0.20 & -0.01 & -0.31 & -0.21 \\
\hline Liberia & LBR & 0 & 0 & 0 & 43.98 & -0.60 & n.a. & -0.31 & -0.20 \\
\hline $\begin{array}{l}\text { Macao SAR, } \\
\text { China }\end{array}$ & MAC & 0 & 0 & 0 & 11.61 & -0.17 & 0.01 & -2.73 & -0.15 \\
\hline $\begin{array}{l}\text { Macedonia, } \\
\text { FYR }\end{array}$ & MKD & 0 & 0 & 0 & 54.68 & -1.98 & -0.17 & -0.28 & -0.26 \\
\hline
\end{tabular}




\begin{tabular}{|c|c|c|c|c|c|c|c|c|c|}
\hline Madagascar & MDG & 0 & 0 & 0 & 22.81 & -0.82 & -0.07 & -0.87 & -0.70 \\
\hline Malawi & MWI & 0 & 0 & 0 & 42.80 & -0.03 & -0.05 & -0.28 & -0.22 \\
\hline Malaysia & MYS & 0 & 0 & 0 & 69.50 & -0.03 & -0.01 & -2.20 & 3.60 \\
\hline Maldives & MDV & 0 & 0 & 0 & 42.04 & -0.01 & -0.06 & -1.12 & -0.20 \\
\hline Mali & MLI & 0 & 0 & 0 & 24.55 & -1.20 & -0.17 & -0.65 & -0.70 \\
\hline Marshall & MHL & 0 & 0 & 0 & 47.97 & 0.23 & n.a. & -2.34 & -1.49 \\
\hline \multicolumn{10}{|l|}{ Islands } \\
\hline Mauritania & MRT & 0 & 0 & 0 & 63.11 & -1.50 & n.a. & -0.51 & -0.87 \\
\hline Mauritius & MUS & 0 & 0 & 0 & 37.43 & -0.80 & -0.07 & -0.81 & -0.69 \\
\hline Mexico & MEX & 0 & 1 & 1 & 31.89 & -2.56 & -0.22 & -0.17 & -1.13 \\
\hline Micronesia, & FSM & 0 & 0 & 0 & 37.56 & 0.22 & n.a. & -2.87 & -1.79 \\
\hline \multicolumn{10}{|l|}{ Fed. Sts. } \\
\hline Moldova & MDA & 0 & 0 & 0 & 50.84 & -0.88 & -0.08 & -0.43 & -0.40 \\
\hline Mongolia & MNG & 0 & 0 & 0 & 54.15 & 0.07 & 0.00 & -2.77 & -0.78 \\
\hline Morocco & MAR & 0 & 1 & 1 & 34.13 & -2.00 & -0.17 & -0.01 & -0.52 \\
\hline Mozambique & MOZ & 0 & 0 & 0 & 38.26 & -0.42 & -0.04 & -0.50 & -0.39 \\
\hline Namibia & NAM & 0 & 0 & 0 & 41.50 & -1.00 & -0.10 & -0.70 & -0.73 \\
\hline Nepal & NPL & 0 & 0 & 0 & 19.67 & -0.15 & -0.08 & -1.16 & -0.14 \\
\hline New Zealand & NZL & 0 & 0 & 0 & 22.06 & -0.46 & -0.04 & 2.59 & 12.66 \\
\hline Nicaragua & NIC & 0 & 1 & 1 & 40.58 & -2.31 & -0.20 & 0.08 & -1.15 \\
\hline Niger & NER & 0 & 0 & 0 & 32.48 & -1.10 & -0.06 & -0.64 & -0.64 \\
\hline Nigeria & NGA & 0 & 0 & 0 & 31.42 & -0.66 & -0.06 & -0.45 & -0.43 \\
\hline Norway & NOR & 0 & 1 & 0 & 24.71 & -1.91 & -0.17 & -0.29 & -0.27 \\
\hline Pakistan & PAK & 0 & 0 & 0 & 15.27 & -0.19 & -0.02 & -1.43 & -0.14 \\
\hline Palau & PLW & 0 & 0 & 0 & 32.18 & 0.22 & 0.01 & -2.35 & -1.40 \\
\hline Panama & PAN & 0 & 1 & 1 & 54.34 & -1.94 & -0.15 & -0.04 & -0.90 \\
\hline Papua New & PNG & 0 & 1 & 0 & 38.33 & -1.27 & -0.11 & -1.48 & -1.04 \\
\hline \multicolumn{10}{|l|}{ Guinea } \\
\hline Paraguay & PRY & 0 & 0 & 0 & 36.77 & -0.62 & -0.06 & 0.00 & -0.25 \\
\hline Peru & PER & 0 & 1 & 1 & 21.64 & -1.64 & -0.15 & -0.26 & 0.89 \\
\hline Philippines & PHL & 0 & 0 & 0 & 23.45 & -0.08 & -0.01 & -2.71 & -1.31 \\
\hline Russian & RUS & 0 & 0 & 0 & 21.46 & -1.01 & -0.08 & -0.92 & -0.64 \\
\hline \multicolumn{10}{|l|}{ Federation } \\
\hline Rwanda & RWA & 0 & 0 & 0 & 17.39 & -1.12 & -0.03 & -0.75 & -0.74 \\
\hline Samoa & WSM & 0 & 0 & 0 & 30.83 & 0.32 & n.a. & -2.36 & -1.48 \\
\hline Sao Tome and & STP & 0 & 0 & 0 & 28.66 & -0.63 & n.a. & -0.50 & -0.36 \\
\hline \multicolumn{10}{|l|}{ Principe } \\
\hline Saudi Arabia & SAU & 0 & 0 & 0 & 37.28 & -0.88 & -0.08 & -0.78 & -0.63 \\
\hline Senegal & SEN & 0 & 0 & 0 & 31.86 & -1.22 & -0.12 & -0.61 & -0.70 \\
\hline Seychelles & SYC & 0 & 0 & 0 & 57.44 & -0.14 & n.a. & -0.45 & -0.29 \\
\hline Sierra Leone & SLE & 0 & 0 & 0 & 31.61 & -0.49 & -0.05 & -0.30 & -0.15 \\
\hline Singapore & SGP & 0 & 0 & 1 & 143.45 & -0.04 & -0.01 & -1.99 & 4.04 \\
\hline
\end{tabular}




\begin{tabular}{|c|c|c|c|c|c|c|c|c|c|}
\hline Solomon & SLB & 0 & 0 & 0 & 48.09 & 0.28 & 0.02 & -2.28 & -1.49 \\
\hline \multicolumn{10}{|l|}{ Islands } \\
\hline South Africa & ZAF & 0 & 1 & 0 & 27.32 & -1.69 & -0.14 & -0.52 & -0.52 \\
\hline Sri Lanka & LKA & 0 & 0 & 0 & 24.04 & -0.20 & -0.02 & -1.39 & -0.24 \\
\hline St. Kitts and & KNA & 0 & 1 & 0 & 17.93 & -0.35 & -0.09 & -0.55 & -0.38 \\
\hline \multicolumn{10}{|l|}{ Nevis } \\
\hline St. Lucia & LCA & 0 & 1 & 0 & 35.93 & -0.29 & n.a. & -0.54 & -0.35 \\
\hline St. Vincent and & VCT & 0 & 1 & 0 & 27.65 & -0.84 & n.a. & -0.73 & -0.82 \\
\hline \multicolumn{10}{|l|}{ the Grenadines } \\
\hline Sudan & SDN & 0 & 0 & 0 & 10.38 & -0.40 & -0.04 & -0.43 & -0.32 \\
\hline Suriname & SUR & 0 & 1 & 0 & 41.90 & -0.99 & -0.19 & -0.14 & -0.42 \\
\hline Swaziland & SWZ & 0 & 0 & 0 & 51.41 & 0.07 & -0.02 & -0.40 & -0.08 \\
\hline Switzerland & CHE & 0 & 1 & 0 & 33.54 & -2.02 & -0.17 & -0.52 & -0.49 \\
\hline Syria & SYR & 0 & 1 & 0 & 12.36 & -1.30 & -0.12 & -0.11 & 0.07 \\
\hline Tajikistan & TJK & 0 & 0 & 0 & 33.65 & 0.04 & -0.01 & -0.15 & -0.13 \\
\hline Tanzania & TZA & 0 & 0 & 0 & 29.41 & -0.40 & -0.03 & -0.50 & -0.38 \\
\hline Thailand & THA & 0 & 0 & 0 & 65.18 & -0.09 & -0.01 & -2.56 & -1.16 \\
\hline Togo & TGO & 0 & 0 & 0 & 36.71 & -0.44 & -0.05 & -0.22 & -0.13 \\
\hline Tonga & TON & 0 & 0 & 0 & 23.96 & 0.27 & 0.02 & -2.16 & -1.50 \\
\hline Trinidad and & TTO & 0 & 0 & 0 & 48.24 & -1.03 & n.a. & 0.11 & -0.53 \\
\hline \multicolumn{10}{|l|}{ Tobago } \\
\hline Tunisia & TUN & 0 & 1 & 0 & 45.39 & -1.56 & n.a. & 0.01 & 0.02 \\
\hline Turkey & TUR & 0 & 1 & 0 & 24.65 & -1.56 & -0.14 & -0.32 & -0.24 \\
\hline Turkmenistan & TKM & 0 & 0 & 0 & 36.54 & -0.36 & n.a. & -0.25 & -0.23 \\
\hline Tuvalu & TUV & 0 & 0 & 0 & 31.72 & 0.26 & 0.13 & -2.74 & -1.76 \\
\hline Uganda & UGA & 0 & 0 & 0 & 20.78 & -0.94 & -0.08 & -0.69 & -0.66 \\
\hline Ukraine & UKR & 0 & 0 & 0 & 43.44 & -0.77 & -0.07 & -0.41 & -0.38 \\
\hline Uruguay & URY & 0 & 0 & 0 & 20.39 & -0.53 & -0.05 & -0.30 & -0.36 \\
\hline Uzbekistan & UZB & 0 & 0 & 0 & 21.62 & 0.01 & -0.03 & -0.34 & 0.00 \\
\hline Vanuatu & VUT & 0 & 0 & 0 & 22.23 & 0.40 & 0.04 & -2.51 & -1.58 \\
\hline Venezuela, RB & VEN & 0 & 0 & 0 & 20.63 & -1.47 & -0.07 & 0.14 & -0.69 \\
\hline Vietnam & VNM & 0 & 0 & 0 & 73.28 & -0.01 & -0.01 & -2.66 & 3.75 \\
\hline Yemen, Rep. & YEM & 0 & 0 & 0 & 28.76 & -0.36 & 0.00 & -0.76 & -0.38 \\
\hline Zambia & $\mathrm{ZMB}$ & 0 & 0 & 0 & 40.19 & 0.00 & -0.07 & -0.37 & -0.20 \\
\hline Zimbabwe & ZWE & 0 & 0 & 0 & 41.83 & -0.42 & n.a. & -0.44 & -0.38 \\
\hline
\end{tabular}

Source: Authors' calculations. 


\section{WEB APPENDIX}

Table A2. Summary statistics (2012) for small sample $(C=146)$

\begin{tabular}{lrrrrr}
\hline \hline & Mean & \multicolumn{1}{c}{ p50 } & \multicolumn{1}{c}{ Std.dev. } & min & \multicolumn{1}{c}{$\max$} \\
\hline Exports (mn USD), X & 747.47 & 1.09 & 6933.75 & 0.00 & 444407.20 \\
Active exports, dummy (0,1), II & 0.80 & 0.00 & 0.40 & 0.00 & 1.00 \\
PTA, dummy (0,1), PT A & 0.19 & 0.00 & 0.40 & 0.00 & 1.00 \\
Geographical distance, logDIST & 8.76 & 8.96 & 0.77 & 4.11 & 9.89 \\
Contiguity, dummy (0,1), BORD & 0.02 & 0.00 & 0.14 & 0.00 & 1.00 \\
Common language, dummy (0,1), LANG & 0.13 & 0.00 & 0.34 & 0.00 & 1.00 \\
Common colonizer, dummy (0,1), COLONY & 0.09 & 0.00 & 0.29 & 0.00 & 1.00 \\
Tariff (\%) & 7.43 & 7.14 & 5.48 & 0.00 & 33.36 \\
\hline Number of observations & 21,170 & & & & \\
\hline \hline
\end{tabular}

Notes: The trade data come from UN Comtrade and refer to the year of 2012. The PTA dummy takes value one if a regional trade agreement between two countries has been notified to the WTO.

The other variables are from CEPII. 
Table A3. Parameters of the trade cost function, full detail

\begin{tabular}{|c|c|c|c|c|c|c|c|c|}
\hline & \multicolumn{5}{|c|}{ Selection (two stage) } & \multicolumn{3}{|c|}{ No selection } \\
\hline & $\begin{array}{c}\text { [1] } \\
\text { Pre- } \\
\text { ferred }\end{array}$ & $\begin{array}{c}{[2]} \\
\mathbf{H M}\end{array}$ & $\begin{array}{c}{[3]} \\
\text { FMNPT }\end{array}$ & $\begin{array}{c}{[4]} \\
\text { Tariffs } \\
\text { only }\end{array}$ & $\begin{array}{c}\text { [1'] } \\
\text { Pre- } \\
\text { ferred }\end{array}$ & $\begin{array}{l}{\left[2^{\prime}\right]} \\
\mathbf{H M}\end{array}$ & $\begin{array}{c}{\left[3^{\prime}\right]} \\
\text { FMNPT }\end{array}$ & $\begin{array}{c}\text { [4'] } \\
\text { Tariffs } \\
\text { only }\end{array}$ \\
\hline PTA & 1.21 & 0.36 & 0.12 & 1.21 & 1.21 & 0.36 & 0.12 & 1.21 \\
\hline $\log$ DIST & $\begin{array}{l}-0.50 \\
(0.03)\end{array}$ & -1.10 & $\begin{array}{l}-0.50 \\
(0.03)\end{array}$ & $\begin{array}{l}-0.49 \\
(0.03)\end{array}$ & $\begin{array}{l}-0.49 \\
(0.03)\end{array}$ & -1.10 & $\begin{array}{l}-0.49 \\
(0.03)\end{array}$ & $\begin{array}{l}-0.49 \\
(0.03)\end{array}$ \\
\hline BORD & $\begin{array}{c}0.2 \\
(0.08)\end{array}$ & 0.66 & $\begin{array}{c}0.2 \\
(0.08)\end{array}$ & $\begin{array}{c}0.2 \\
(0.08)\end{array}$ & $\begin{array}{c}0.2 \\
(0.08)\end{array}$ & 0.66 & $\begin{array}{c}0.2 \\
(0.08)\end{array}$ & $\begin{array}{c}0.20 \\
(0.08)\end{array}$ \\
\hline LANG & $\begin{array}{c}0.19 \\
(0.08)\end{array}$ & 0.39 & $\begin{array}{c}0.19 \\
(0.08)\end{array}$ & $\begin{array}{c}0.20 \\
(0.09)\end{array}$ & $\begin{array}{c}0.19 \\
(0.08)\end{array}$ & 0.39 & $\begin{array}{c}0.19 \\
(0.08)\end{array}$ & $\begin{array}{r}0.20 \\
(0.09)\end{array}$ \\
\hline COLONY & $\begin{array}{c}0.71 \\
(0.17) \\
\end{array}$ & 0.75 & $\begin{array}{c}0.71 \\
(0.17) \\
\end{array}$ & $\begin{array}{c}0.76 \\
(0.18) \\
\end{array}$ & $\begin{array}{c}0.71 \\
(0.17) \\
\end{array}$ & 0.75 & $\begin{array}{c}0.71 \\
(0.17) \\
\end{array}$ & $\begin{array}{c}0.77 \\
(0.18) \\
\end{array}$ \\
\hline \multicolumn{9}{|c|}{ Selection equation (Probit) } \\
\hline PTA & $\begin{array}{c}0.00 \\
.\end{array}$ & $\begin{array}{c}0.00 \\
.\end{array}$ & $\begin{array}{c}0.00 \\
.\end{array}$ & $\begin{array}{c}0.00 \\
.\end{array}$ & & & & \\
\hline $\log$ DIST & $\begin{array}{l}-0.79 \\
(0.03)\end{array}$ & $\begin{array}{l}-0.79 \\
(0.03)\end{array}$ & $\begin{array}{l}-0.79 \\
(0.03)\end{array}$ & $\begin{array}{l}-0.81 \\
(0.03)\end{array}$ & & & & \\
\hline BORD & $\begin{array}{l}-0.64 \\
(0.16)\end{array}$ & $\begin{array}{l}-0.64 \\
(0.16)\end{array}$ & $\begin{array}{l}-0.64 \\
(0.16)\end{array}$ & $\begin{array}{l}-0.12 \\
(0.2)\end{array}$ & & & & \\
\hline LANG & $\begin{array}{c}0.16 \\
(0.05)\end{array}$ & $\begin{array}{c}0.16 \\
(0.05)\end{array}$ & $\begin{array}{c}0.16 \\
(0.05)\end{array}$ & $\begin{array}{c}0.20 \\
(0.07)\end{array}$ & & & & \\
\hline COLONY & $\begin{array}{c}0.36 \\
(0.05) \\
\end{array}$ & $\begin{array}{c}0.36 \\
(0.05) \\
\end{array}$ & $\begin{array}{c}0.36 \\
(0.05) \\
\end{array}$ & $\begin{array}{c}0.33 \\
(0.06) \\
\end{array}$ & & & & \\
\hline Pseudo $R^{2}$ & 0.93 & & & & 0.93 & & & \\
\hline
\end{tabular}

